\title{
Network Analysis of Actors and Policy Keywords for Sustainable Environmental Governance: Focusing on Chinese Environmental Policy
}

\author{
Dan Zhang ${ }^{1,+}$, Fan Fan ${ }^{1, \dagger}$ and Sang Do Park ${ }^{2, *}$ \\ 1 School of International Business Management, Woosong University, 171, Dongdaejeon-ro, Dong-gu, \\ Daejeon 34606, Korea \\ 2 Department of Global Business, Konkuk University, 120, Neungdong-ro, Gwangjin-gu, Seoul 05029, Korea \\ * Correspondence: sdpark@konkuk.ac.kr; Tel.: +822-450-4067 \\ + Dan Zhang and Fan Fan are co-first authors.
}

Received: 13 May 2019; Accepted: 25 July 2019; Published: 27 July 2019

\begin{abstract}
Environmental issues are viewed as a serious problem with a complex network structure involving various stakeholders. Environmental governance is considered the most reasonable way to promote environmental policy, and it is an important mechanism contributing to the sustainable development of society. Through the network analysis of actor and policy keywords, this study demonstrated whether environmental governance policies are being pursued through the cooperation of various participants in China, the epicenter of global environmental issues. We collected text big data from 2001 to 2018 under the theme of "environmental policy" on the main online portal web in China. Through text mining, key actors and policy keywords were selected according to the timing of environmental policy promotion, and network analysis and core-periphery analysis were conducted based on this actor/keywords data set. The results of this study are as follows. First, China's environmental policy is a rudimentary governance cooperation structure, and the central and local governments are still the main policy-promoting actors. Second, the fundamental solution of the environmental problem through readjustment of the environment-related system and industrial restructuring has become the keyword for China's implementation of environmental policy at present. Third, there were certain words, such as social, public, enterprise, and institution, in the aspects of environmental governance, while these words failed to be at the center of multi-dimensional scaling (MDS) analysis for the actors. This result shows that environmental governance and network are still at an early stage and that the Chinese government's strong power lies in its environmental policy. Based on these results, policy recommendations are presented.
\end{abstract}

Keywords: environmental governance; China's environmental policy; text-mining; network analysis; core-periphery analysis

\section{Introduction}

It is necessary for countries to systematically identify the nature of environmental issues and effectively cope with them to defend the interests of the state and secure sustainable development. The causal relationships of modern environmental issues are difficult to determine because of their complexity, circulation, and the interactions of pollutants [1-4]. Moreover, damage to ecosystems that stems from environmental pollution has far-reaching consequences that go well beyond short-term damage. This trend implies that solutions to environmental issues must be devised through an understanding of the various factors and their three-dimensional interrelationship rather than a plain two-dimensional relationship. As part of the efforts to understand and solve environmental problems, 
consistent attempts have been made to solve them using technical rationality through natural science (e.g., [5,6]), a technological engineering approach (e.g., [7-10]), and an economic approach (e.g., [6,11,12]). Research has also been undertaken toward solving ultimate environmental issues based on the interpretation of the lifestyle and quality of life of participants in environmental policies (e.g., [6,13,14]). However, environmental issues need solutions developed through integrated approaches among fields owing to the uncertainty, complexity, long-range, transboundary, and irreversible nature of pollution. This is the reason for which the environmental governance approach, which takes along various entities to participate in the formulation and implementation of environmental policies on solving environmental issues, has been gaining persuasive power.

Environmental governance is a dynamic process in which conflicts and interests among various participants are negotiated and coordinated. This is because it has properties that many actors are involved in, as well as going through the process of complicated mutual adjustment to solve issues of concern $[4,15,16]$. In this context, environmental governance can be regarded as an important policy mechanism for solving environmental issues within the ambit of the mutual relationships of various actors who influence environmental policies [16-18]. In this respect, environmental governance means multilateral relationship formation for solving environmental issues, as well as its evolution into cooperation and governance beyond the phase of multiple competitions and conflicts surrounding environmental issues. Therefore, consensus and cooperation among various concerned actors achieve greater recognition than the simplistic establishment, implementation, and interpretation of environmental policies to solve environmental issues. It is necessary to establish a network that focuses on the coexistence and symbiosis of all actors affecting the environment by breaking from being regulation-oriented, which is considered to involve simplistic government decisions.

From the network perspective, it is not that only selective subject areas should propose solutions to environmental issues but that all subjects surrounding the issues need to participate in problem-solving $[19,20]$. In this process, it is necessary to focus on the actors involved in promulgating environmental policies and their roles with regard to environmental issues. It is because policy directions and solutions vary depending on which actors play what kind of role in the policy network surrounding environmental policies. Differences in the positions of environmental policy actors indisputably remain, depending on whether their interests and objectives are in congruence with particular environmental policies. The important facts are that network attributes between actors remain the same regardless of whether they are in favor of or against environmental policies and there are major actors leading the other actors in the network [21]. Such major actors have the capability to exert positive and negative influences on environmental policies, and we need to identify those actors and strengthen policy support for them in parallel for the positive resolution of environmental policies.

This study selected China's environmental policy as a target of analysis. China has emerged as one of the G2 backed by its rapid economic growth but faced criticism of its dismissal of environmental issues that have driven economic gains at a cost $[22,23]$. Even though China has strongly protested such criticism, claiming that this is a typical example of 'kicking away the ladder' ('kicking away the ladder' refers to the way that countries that have already joined the ranks of economically advanced countries express their wariness of a latecomer's rapid growth by applying various global standards [24]). China is no longer free from global and local environmental issues. As of today, Chinese leaders are aware of the seriousness of environmental issues and have emphasized problem-solving according to environmental governance regarding the participation of every section of society as being important as, in 2002, China's people's Congress declared the "green growth" policy that highlights efficiency and harmony of the economy, environment, and society [25,26]. In contrast with the superficial splendor of the declaration, of course, as evidenced by "sustainable development" and "green growth", which aim at harmonizing economic development and environmental conservation in China, practical effects of environmental policies have faded away owing to top-down policies (e.g., environmental regulations) and opposing interests, including those in the leadership within the Communist Party—central and local governments—and environmental regulators and enterprises. 
However, since China has strong policy implementation, it is expected to maximize the efficiency and effectiveness of policy implementation by promoting government-led, rapid environmental policies while implementing environmental governance measures $[18,27,28]$. This has the potential to become an important milestone in dealing with environmental issues for various developed and developing countries that encounter contradictions between environmental issues and economic development. Therefore, it is significant to study China's environmental policies. Differences certainly lie in the level of environmental issue recognition, the intensity, and the roles of actors in promoting environmental policies by each state. However, it is an undeniable fact that countries accepting policies related to environmental issues show path dependency on environmental governance measures regardless of the methodologies from advanced countries or developed/undeveloped countries. Thus, it is worth noting that China, a leader of developing countries, has solved problems with strong environmental governance and that it is appropriate and timely from academic and practical perspectives to analyze the major actors and their roles that emerged in this process.

Based on this perspective, this study analyzes the network of actors, major actors, and major policy keywords that affect policies by collecting big data on environmental policy texts. This study aims to identify which actors played an important role in China claiming to advocate environmental governance in solving environmental issues and what their network attributes mean for each economic policy implementation cycle (every five years). This study complements the existing studies at the content level, conducts an extensive investigation into the actors and influencing factors promoting environmental policies, and distinguishes itself from the methodological perspective that performs empirical analysis based on big data, by expanding the literature review, theoretical studies, and case studies.

The composition of the paper is as follows. In Chapter 2, this study examines the previous studies on environmental governance through theoretical studies and classifies the actors that affect the environmental policies of China. Chapter 3 explains the data and theoretical model, and Chapter 4 carries out the big data empirical analysis based on the theoretical model. Lastly, Chapter 5 presents conclusions and implications based on empirical analysis results.

\section{Theoretical Review}

China has been receiving attention as a source of global environmental issues since the 2000s. China established environmental policies at a national level relatively earlier in comparison to its level of economic development, while its application and enforcement have been extremely passive, even though its 11th Five-Year Plans (FYPs) emphasized a transition into developmental strategies focused on "resource-saving and environment-friendly social construction". Though China has established a relatively advanced legal system related to environmental protection, it has focused more on quantitative growth goals, such as economic growth and industrial development [29,30]. In particular, the local governments- the actual promoters of environmental policies—showed considerable disparity in the strategic orientation between quantitative growth and environmental protection, depending on the level of economic development in the region, the industrial structure, the level and targets of urbanization, the type and degree of environmental pollution, and willingness and capacity of environmental improvement [31]. Thus, the environmental protection policies of some large cities were only partially implemented, leading to environmental pollution problems throughout China.

Water pollution is one of the most serious environmental issues in China. According to the data of the Ministry of Environmental Protection of the People's Republic of China in 2016, two-thirds of the groundwater and one-half of the surface water are severely polluted. Moreover, China is the country with the most serious shortage of water resources. Its total amount of freshwater resources ranks 6th in the world, while the freshwater resources per capita rank 100th to 117th with approximately $2000 \mathrm{~m}^{3}$, which is only half of the global average. Although $70 \%$ of 1.3 billion people in China drink groundwater, the problem is that the majority of the groundwater is contaminated [31,32]. Therefore, since 2015, China's State Council implemented the Water Pollution Prevention and Control Action Plan to increase the number of urban sewage treatment facilities, strengthen the crackdown on the unauthorized 
discharge of wastewater, and purify the rivers. Through this plan, China aims to raise the water quality of $70 \%$ or higher of the basins of the seven rivers, including the Yangtze River and Yellow River, to an excellent level by 2020 [33].

In the case of air pollution, which is highly correlated with energy use, China, the world's greatest energy consumer, topped the US in 2011 to become the world's largest greenhouse gas emitter. Among the resources, its sulfur dioxide and nitrogen oxide emissions are the highest in the world owing to the country's heavy dependence on coal for energy, which inflicts severe damage on the neighboring countries [34]. According to the Chinese authorities' data concerning air pollution in major regions at the end of 2017, which had been released by the East Asia office of Greenpeace (an international environmental organization), 256 cities (70.1\%) out of the 365 major cities had not met the government air pollution standard. Moreover, the PM 2.5 values in 128 cities were twice higher than the standard. The direct economic loss caused by such air pollution is estimated as at least RMB 23 billion [35]. Therefore, the Chinese government has pursued policies for improving air quality by selecting the key management areas by region. The Beijing-Tianjin-Hebei (BTH) region, including 13 cities, such as Beijing, Tianjin, and Hebei, have been selected as priority control targets for air pollution to reduce the PM 2.5 concentration by 25\% compared to that of 2012. Besides the BTH region, the Yangtze River Delta and the Pearl River Delta, where large major cities, such as Shanghai and Guangzhou, are central, respectively, have high concentrations of air pollutant emissions. Thus, the Chinese government is pursuing a more strict air pollution control policy in those regions in comparison to other regions by selecting these two regions along with the BTH region as the three priority control regions for air pollution, with the aim of reducing the PM 2.5 concentration by $20 \%$ and $15 \%$, respectively, until 2017 .

One of the crucial points to note in the policy process of such a radical environmental improvement is that China's environmental issues are handled under the government lead rather than cooperation among the central and local governments and private (enterprise and environmental groups) sectors. China is a representative country executing strong policy enforcement under the auspices of authoritarian environmentalism. China has focused its authority on a small number of government enforcement agencies based on its competent bureaucratic organizations, to adopt a state-led approach limiting public participation in the policy enforcement process [36]. Obviously, since the Paris Agreement, the formulation and enforcement of environmental policies have departed from a project-based approach and have been conducted comprehensively. In other words, China has implemented short- and long-term policies that integrate various areas, such as industrial restructuring on the macro-level approach, energy sources conversion, and development of the IT and service industry. However, the Chinese central government has achieved effective enforcement through top-down governance and centralization, which does not decentralize the decision-making power of local governments and civil society in the environmental policy enforcement process [37].

Recently, China has been promoting the bottom-up governance of environmental policies as its decentralized system. For example, in the area of air pollution, inclusive governance with stronger involvement of media, NGOs, and the public is underway [34]. However, bounded rationality as well as cognitive limitations, which include a lack of environmental information in central government-local governments, local government-local governments, and national-social relations [38], and shortage of available time, have been obstacles to genuine environmental governance [32]. Although, in the policy process for improving the environment, rapid policy enforcement is possible without strong institutionalized stakeholders [39], the political context of a particular department, such as the trend that economic growth is more important than environmental issues, has determined the environmental policy costs and benefit distribution due to the power inequality within the Chinese government [40]. Furthermore, the frequent shifts of personnel of the local governments who promote environmental policies have also had a negative impact on establishing stable environmental policies and environmental governance [30].

Nevertheless, China demonstrates its commitment to sustainable development through the solution of its environmental governance. Environmental governance is a management system in 
which market organizations (business) and civil society deviate from the former government-led system and participate and cooperate in the process of setting goals for solving environmental issues, seeking and determining policy alternatives, and implementing and evaluating these alternatives. China's environmental issues have developed into severe problems, and environmental governance as resolution strategies involving various subjects from a long-term perspective has become indispensable.

Among the various types of environmental governance, cooperative management is emphasized as a new governance mechanism. According to the ideas of Delmas and Young [41], who analyzed environmental governance by creating a system diagram (see Figure 1) focusing on the relationships of members of society, including the public sector, the private sector, and civil society, in terms of cooperative management, cooperation, including public volunteer programs (e.g., public-private partnerships); joint resource management (e.g., public-social partnerships); third initiatives (e.g., private-social partnerships); and eco-labels (e.g., public-private-social partnerships), is more effective in solving environmental problems than the self-activities of each sector (e.g., intergovernmental organizations, self-regulation programs, and global international society). Of course, the power of the three sectors balanced by governance is the ideal structure of the environmental governance system. However, it is undeniable that certain imbalances in power and roles of each sector occur depending on the characteristics of countries. Particularly, advanced countries and developing countries reveal a stark contrast of power and roles in terms of promoting environmental policies. It is fundamental to study the role of actors in each sector and to clarify the organic network relationship.

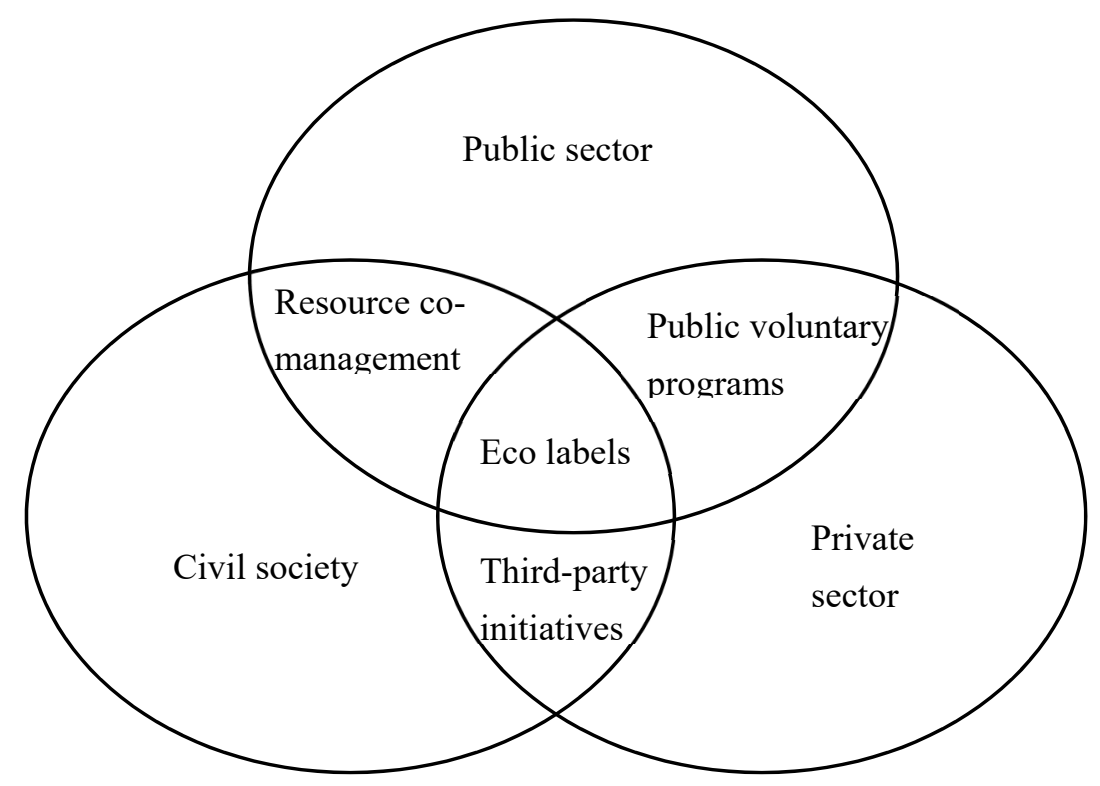

Figure 1. Diagram of the environmental governance system. Note: State and federal governments and intergovernmental organizations for the public sector; NGOs, community, etc. for civil society; trade associations, investors, consumers, etc. for the private sector. Source: Delmas and Young [41].

Recent studies on China's environmental protection policies have been actively implemented inside and outside of the entirety of China, but most of them have stagnated in the exploratory stage. Domestic studies undertake rare empirical studies, emphasize problem identification in environmental regulations, and emphasize the introduction of measures for policies and legislation improvements at the normative level. Getting into the specifics of major studies, relatively, there have been many studies focusing on regulations in China because of its lack of systematic legislation related to the environment until recently. In the spectrum of environmental policies, there are studies on the evolvement and features of environmental policies in China [42], changes in environmental policies since the foundation of the country [43], and the direction of change in environmental policies [44]. Meanwhile, studies suggesting the need for private sector participation have been introduced to overcome the limitation of 
environmental regulations. Although a considerable number of studies of environmental issues in China have accumulated, they rarely provide comprehension obtained from overall and contextual analysis of the environmental policy decision-making system and implementation and are limited to partial or disconnected phases.

In contrast, studies outside China have focused on the relationship between the political context and environmental policy actors. The representatives are the study of the characteristics of environmental policy promotion of Chinese politics by approaching environmental issues from the political perspective [27,45], as well as the study of environment-related legal systems and policies [46]. Studies in recent years have started reflecting the trend of approaching environmental issues from the perspective of environmental governance, which explores private participation areas of China's environmental issues. The studies on analyzing the evolution of environmental NGOs in China by using the political process model [47]; exploring the applicability of the global standard to China by analyzing the relationship between China's domestic environment governance and global governance $[17,48]$; and conducting structural analysis and observing the relationship among China's policymaking system, executive system, and actors $[18,26,45]$ are exemplary.

Consequent to the application of the trends of previous studies on China's environmental policies, these policies have garnered growing attention both at home and abroad, and its studies have been accumulated. However, most of the studies limit their focus to partial perspectives, which hinders them from reaching a holistic perspective, such as that of an environmental policy network. Its various actors related to environmental issues that require careful observation when a strong centralized state, such as China, emphasizes policies and role orders to achieve short-term and long-term performance, mainly in a top-down manner. It is because policymakers emphasize the coexistence of actors or the building of networks focusing on symbiosis in the process of a governance approach to solve wicked problems, including environmental issues, which poses the question as to how to define the scope of actors and participants. China also underlines a governance approach to environmental issues and encourages the participation of various members. It is considered to be a change at the national level to promote advanced policy formation and implementation that highlights social consensus on a long-term basis instead of hankering for short-term tangible results produced by the existing top-down policy implementation. Therefore, we present the following study questions:

RQ1: Which actors are most central in the development of China's environmental policy?

Following the investigation of cooperative mechanisms for the actors' mutual network, it is crucial to examine the sequential temporal changes of network structures among the actors in the environmental governance mechanism for solving environmental issues. Environmental governance is the application of environmental issues to governance principles and realization methods, including participation, partnership, democracy, openness, and mutual cooperation, appearing in various forms of networks, depending on the scope and involvement level of stakeholders, partner relationships, interaction intensity, and the linkage level between actors $[4,16]$. The structures and properties of networks enable us to understand the interactions among various actors and keywords of major policies involving actors in environmental governance [19]. Regarding our promotion of environmental policies, the time sequential changes of network structures and properties explain the policy stream from the past to the present as to how policies have been implemented and provide important indicators for future direction. Therefore, tracing the development of actors involved in environmental issues, as well as network structure and property changes of policy keywords, is an important task from the perspective of predicting the future based on past and present environmental policies. Therefore, we can derive the following study problems:

RQ 2: How are China's environmental policy actors/keywords changing by the policy cycle?

RQ 3: Which actors/policy keywords play a key role in China's environmental policy? 
In this study, to identify these three problems, theoretical discussions on major actor groups related to environmental issues are preemptively reviewed.

\subsection{Central Government}

The central government, representing the bureaucracy, plays a key role in the environmental policymaking and implementation process with its expertise backed by organizational, information, and technical powers [49]. Since environmental affairs involve individual ministries, organic cooperation between environmental regulatory agencies and relevant ministries is essential to enforce environmental regulations. In many cases, however, relevant ministries actually remain obstacles to solving environmental issues and promoting policies, tendencies of which appear relatively stronger in economic ministries; that is, economic ministries play a powerful role in the containment of environmental regulatory policies backed by their relatively high level of status and great power within the government when compared with those of environmental ministries. Works related to environmental policies including regulations and environmental protection are often scattered across ministries because of the diffuseness of environmental issues; hence, conflicts may arise in the process of authority adjustment to efficiently promote environmental policies. Additionally, differences in role perception or policy orientation between economic ministries and environmental regulatory agencies also cause conflicts, and environmental regulatory agencies and economic ministries are different from each other in representing customers or beneficiary groups. Therefore, those institutions have an antagonistic relationship with each other because of their distinctively different political support groups. The implementation of particular environmental policies is likely to be abandoned or delayed for a long time when conflicts and confrontations occur because of disagreements between relevant government agencies or situations in which environmental policies confront other policies arise.

\subsection{Local Government}

Local governments have a considerable impact on environmental policies because environmental issues often capture more heightened attention at the regional level than they do at the national level. Against the backdrop of a time when many state powers claim to be forces for decentralization and localization, the local government's willingness and responsibility for conservation, as well as local development that reflects the interests of the residents, have also been strengthened simultaneously. However, even if local governments are based on the autonomy of local residents, they cannot completely cut off the relationship with the state power. That is, it is challenging for local governments to refuse growth and avoid development under circumstances that the central government adopts policies for a high level of economic growth and vigorously pursues development policies, such as creating an industrial complex on a large scale [50]. It is because the abandonment of growth and development accelerates the downturn in the local economy and deepens regional disparities [51].

What cannot be overlooked are local governments vulnerable to corporate lobbying, which can be regarded as the main cause of environmental pollution. Under the local autonomy system, local governments have a priority interest in regional development projects. To this end, local governments attempt to attract several businesses to promote the employment of local residents and their funding to carry out road network expansion and public development projects [52]. Therefore, without the considerable interest of the residents in the environment, it is conceivable for local governments to lower the pollution standard or to relax the provision of obligation to install pollution prevention facilities for inducing industries.

In China's case, the problems of power imbalance appeared in the relations between the central and local governments and between different local governments, resulting in adverse effects on the actual achievement of the environmental policies [34,37]. First, the central and local governments have implemented environmental policies as a demonstration, which is similar to socialist propaganda or agitation methods. Since the team composition and dates of the central government's surveillance and inspections are disclosed to the press in advance, it is possible that the local governments deceive 
or incompletely disclose its data to the central government according to its personnel size and the date in the preparation process. Furthermore, the central government environmental inspection agencies crack down on the province-level local government for about 10 days, when it is practically impossible to control both environmental regulations and policies in terms of area versus time. Therefore, the supervision of environmental issues in the provinces is inevitably limited because only pre-planned and deliberate materials are reviewed and enforced. As another example, in 2017, Hebei Province converted 2.5 million household heating fuels from coal to natural gas to achieve the central environmental improvement goal. However, the natural gas supply shortage caused the residents to suffer the great inconvenience. The local government conducted policy enforcement just for show in the process of its excessive reaction to the central government's demand.

In the local-to-local government relations, different environmental regulation criteria reflecting regional characteristics have emerged as a problem [29]. To maximize profits, polluting enterprises have been trying to avoid high pollution reduction costs by moving to the western area, which has a less stringent obligation for environmental protection. Thus, the site selection of those enterprises simply serves to redistribute pollution inside China, which hardly helped to improve the overall environment [53]. In particular, local government officials pay attention to the problems of the jurisdiction rather than the environmental issues throughout China, so that enforcement of environmental policies becomes meaningless. For example, Datong city in Shanxi Province moved its polluting plants to a nearby county, which resulted in increasing tax revenue for that county and improving the city's environmental indicators. However, from a macro-level perspective, the effects can hardly be considered to have achieved an environmental improvement in a strict sense [31].

There is also a gap between environmental policy enforcement in urban and rural areas. Although the budgets and personnel of the Ministry of Ecology and Environment are reasonably prepared for the regions on the province, city, and county level, those for the regions below the county level, such as villages and hamlets, are significantly insufficient, which limits the proper enforcement and regulation of environmental policies [37,54]. Therefore, the participation and support of society and enterprises are essential in the base course because it is insufficient to enforce policies based on government capacity alone. However, the regions on the villages and hamlet level, especially agricultural villages, lack institutionalized incentives and governance to encourage society and enterprises to participate in environmental protection. Despite these practical limitations, local governments are important actors in the enforcement and supervision of environmental policies. Especially, local governments in China are the only official organizations that can play a central role in integrating the central government, markets (enterprises), and society (NGOs).

\subsection{Private Enterprise}

In the past, private enterprises were mainly recognized as targets that were subject to important policy implementation groups of environmental policies, as well as variables affecting the policies through various lobbying activities and mobilizing industrial organizations. Private enterprises actively seek to intervene in government policies to mitigate or delay the implementation of government environmental policies, including, in particular, regulatory policies $[55,56]$. This is because private enterprises may face additional costs in the process of solving environmental issues, as well as cumbersome report, approval, and audit procedures, which can act as an impediment to private activities. Conversely, one thing to note here is that not all enterprises necessarily oppose government environmental policies because, in some cases, enterprises find the regulations rather advantageous, and environmental issues lead to technology promotion. If environmental regulations are recognized as having the potential to produce a favorable effect on enterprises, enterprises will not strongly oppose the environmental regulations but will rather regard it as a stimulus to modify the overall corporate strategies [57]. From those perspectives, enterprises will enjoy less conflict with environmental regulatory support groups and positive effects in building eco-friendly and prosocial reputations. 


\subsection{Environmental Organizations}

Among the components of civil society, environmental organizations that exercise the most significant influence on environmental issues mobilize the public with low awareness of the need for environmental protection as groups to support the reinforcement of environmental regulations [58-60]. Those actions apply pressure on the political system to actively solve environmental issues and perform its role as an entrepreneur of environmental regulations to repress corporate groups, the opponents of environmental policies, simultaneously. Environmental organizations also engage in political activities that expose the severity of environmental issues redirected through specific regions or events offering alternatives that are essential for the environmental policymaking process. They also develop various activities, including exerting pressure to establish and enforce policies that strengthen environmental regulations with collateralized political support; accuse enterprises of being involved in direct activities aimed at inducers or contributors of environmental pollution or conduct boycotts of those enterprises' products; and educate or promote the prevention of pollution-inducing activities at home. Those organizations consist of the ones presenting scientific arguments and demonstrating their superiority in the technical aspects, while others focus on advocacy and publicity in the exercise of strategies and methods.

The media, the public, and individuals can be considered as other subjects related to environmental policies. However, the role of the media as a mediator, the public as a beneficiary of environmental policies, and individual voices as the voice of individual opinion have more limited influence than that had by the four major actors mentioned above. Certainly, they are all organically linked and have direct and indirect impacts on environmental policies through mutual influence and interaction. This implies that environmental policy actors in environmental governance are capable of exercising their influence on policies in various ways through the separation and integration process at any time. Therefore, this study examines the analysis of environmental policies in China to observe the actors and their roles in environmental governance revealed through previous studies. This study also performs structural analysis of major actors leading the policies and associated policy keywords through the collection of big data from China's environmental policy related texts, data mining and network analysis, and core-periphery analysis.

\section{Data and Methodology}

Issues are related to topics that attract the attention of many people in a society, including diverse perspectives, actors, and complex networks. The actors' positions on issues cause sharp confrontations and conflicts, and the extended and complicated process of resolutions involve greater social cost. Therefore, it is necessary to investigate and identify the content, options, and the actors' positions on issues and alternatives through accurate analysis of the issues. In the course of this process, the major activities of the actors as well as the main contents of the issues and alternatives are documented in the literature, such as reports, papers, press articles, white papers, or text materials, including questionnaires and interviews [61]. It is possible to build a network of actors in cooperation and conflict relations, or a keyword network of issues with these documents. Among these materials, the language network is established based on the language text that expresses various issues and agendas and actors' interest in alternatives. This network enables multiple interpretations according to the semantic relationships between subject matter keywords or emotional keywords, such as opinions, attitudes, feelings, and tone, selected from the collection of the language texts describing specific positions on major issues and alternatives [62].

This study collects text data on main issues and alternatives that necessarily arise during China's environmental policy establishment, enforcement, public relations process, and conducts network analysis. This is because an analysis of the influence factors or alternatives of issues in various language texts goes beyond simple frequency analysis of keywords and enables network analysis to investigate the relationships between keywords. This methodology is appropriate to identify what influence 
factors play an important role in the level of environmental governance, which inevitably occurs in China's environmental policy enforcement process.

\subsection{Data}

This study analyzes major actors and policy keywords that lead governance networks and policies in China's environmental policies. Textual data on China's "environmental policy" as a keyword was collected through algorithms using Python. The data was collected over the period from 2001 to 2018, when discussion on environmental policy began in earnest in Chinese society. It was divided into four periods and set as analysis units in accordance with China's Five-Year Plans (FYPs), which are representative of macroeconomic-social development policy in China: The 10th FYP (2001-2005); the 11th FYP (2006-2010); the 12th FYP (2011-2015); and the 13th FYP (2016-present). Baidu, Sina blog, and WeChat have designated collection channels as the most representative Internet platforms in China to secure comprehensive trust in text data. China's IT enterprises that provide their representative service: Baidu, a portal site for news, and government documents, Sina-Blog for personal discourse, and WeChat, a social networking service platform specializing in sharing personal opinions and related information through public accounts. Approximately 220,000 environmental policy documents were collected. Except for duplicate documents, the following numbers of documents were secured for each period of China's Five-Year Plans: 11,000 for the 10th FYP; 39,000 for the 11th FYP; 55,000 for the 12th FYP; and 21,000 for the 13th FYP.

\subsection{Text Mining}

This study used text mining that is based on the big data collected to derive the actors and policy keywords that affect Chinese environmental policies. First, unnecessary words, such as verbs, adjectives, and adverbs, were removed from the collected documents, and then, data were refined based on the simultaneous appearance of the words. In the process, this study used the library package of R Studio for morphological analysis. The document is divided into tokens, small semantic units, such as words and phrases [63], and the tag dictionary is used to separate the words that can be analyzed. This technique processes the collected unstructured data into a form of analyzable structured data (see Appendix A). After the data cleaning process, 13,039 words (452 words for the 10th FYP; 1827 words for the 11th FYP; 5,823 words for the 12th FYP; and 4937 words for the 13th FYP) were derived. The study measured the centrality based on those words and identified major actors and policy keywords.

\subsection{Network Analysis and Continuous Core-Periphery Analysis}

Semantic network analysis is a research technique that treats a word as a node in a network and determines whether there is a co-occurrence between certain words [64-66]. Convergence of iterated correlations (CONCOR) analysis, a representative methodology of semantic network analysis, primarily analyzes the correlation metrics of words derived from text mining and presents information about the network type, density, hub node, and cluster group. CONCOR analysis is useful for grouping factors/issues with similar positions and describing the relationships between the groups (see Appendix A). In this study, the correlation metrics for the top 30 words were created based on the appearance frequency and the centrality value, and the network analysis was performed based on these metrics.

The next step places major actors and policy keywords about environmental policies differentiated into two groups, core and periphery, by applying the continuous core-periphery analysis. Among various methodologies for grouping big data to identify patterns and to analyze meanings, this is one of the simplest and most effective models [67,68]. This model is ideal for the investigation of the leading groups of policies among major actors and keywords (see Appendix A). The process provides opportunities to observe the kinds of core-periphery actors and policy keywords that have decentralized China's environmental policies and to intuitively investigate the major actors and policy keywords leading the policies. 


\section{Empirical Analysis Results}

\subsection{The Result of Text Mining}

This study collected text big data on China's environmental policy and further classified and found meaningful policy promoting actors and policy keywords in these data. Based on the coreness score of the words, actors and policy keywords on the top 10 of each period were derived, and the results are presented in Table 1.

Table 1. Environmental policy-promoting actors and policy keywords of each period.

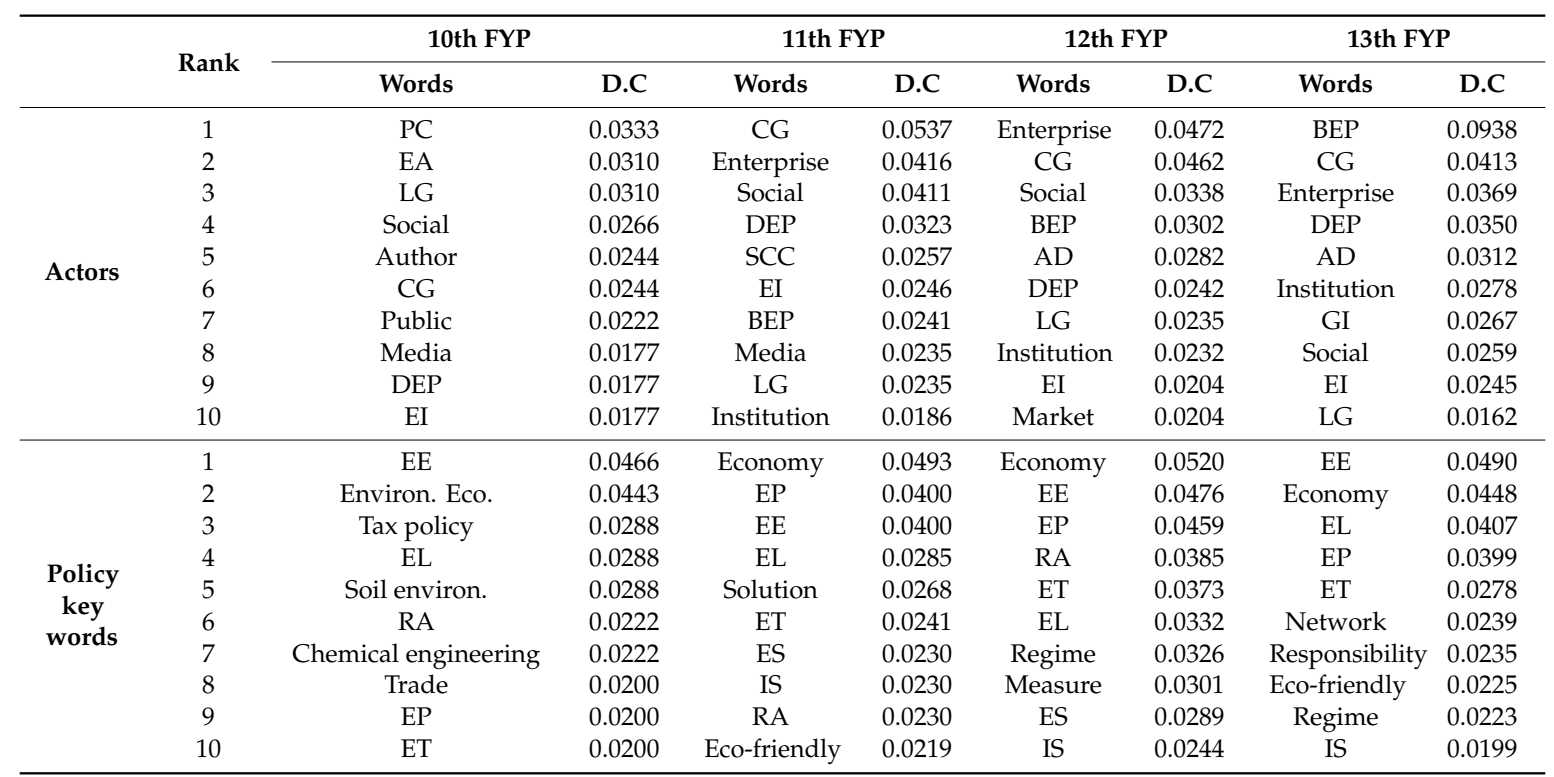

Note: $\mathrm{AD}=$ Administrative Department; $\mathrm{BEP}=$ Bureau of Environmental Protection; $\mathrm{CG}=$ Central Government; D.C $=$ Degree of Centrality; DEP $=$ Department of Environmental Protection; EA = Environmental Administrator; $\mathrm{EE}=$ Ecological Environment; EI = Environment Industry; EL = Environmental Law; EP = Environmental Project; $\mathrm{ES}=$ Environmental Standard $; \mathrm{ET}=$ Environmental Technology; GI = Government-affiliated Institutions; IS = Industrial Structure; LG = Local Government; PC = Publishing Company; RA = Resource Allocation; SCC = State Council of China.

First, in terms of changes in China's environmental policy actors by period, an unusual result appeared that the words, publishing company and author, were highly centralized during the 10th FYP. This can be attributed to the fact that various publishing companies in the early stages of environmental policy implementation initiated social issues through publication and promotion issues related to environmental issues in China. The result indicates that environment-related government sectors have also emerged as major actors and that environmental issues and policies have been highlighted more at the working level of local government and environmental administration than at the central government's environmental policy. The 11th Five-Year Plan was when the international community paid full attention to China's environmental policies in earnest, and the central government led those policies in this period. The significance lies in the fact that the functions of private enterprise and society have become more important than they were in the 10th FYP and that they have emerged as a major actor in leading environmental policies with the government. It implies that attempts to lead environmental policies have been made in the governance network structure led by the central government. During the 12th Five-Year Plan, the functions of the private sector, particularly environment-related enterprises, in environmental policy were emphasized. The government and public institutions certainly remained important actors, and the characteristic of the period is that government and society cooperated with the private-led environmental policy network. Moreover, the market function has been incorporated into the environmental policies as a new actor, which denotes that the market's self-regulating functions are, or should be, operating in environmental issues. Last, the 13th FYP showed that various sectors of the government regained their positions as environmental actors that are passionately leading 
environmental policies. This is a good example of the fact that China's socialist traits still appear strong in environmental policies although it has been promoting its own socialist market economy system. Even though various subjects form networks and claim to support environmental governance, the related government sector still seems to be highly centralized.

The change process of the 10 policy keywords during the same period provides an opportunity to closely investigate how China's environmental policy has evolved. In the period of the 10th FYP, the environmental policies were promoted through a tax imposition policy. In particular, the term "trade" implies that China's environmental policies and pollution are not totally irrelevant to the activities of growth-driven trade expansion that is backed by the manufacturing industry. In terms of environmental policy promotion during the 11th FYP and the 12th FYP, the word "economy" was still pointed out as an important word, which suggested that growth was considered to be more essential than environmental protection. Conversely, various environment-related standards were laid out legally and systematically during the periods, and it signifies the attempts to achieve development by being simultaneously conscious of both economic and environmental aspects. Keywords that emerged during the period of the 13th FYP, including a network for the ecological environment, accountability, and eco-friendliness, demonstrate the efforts to establish environmental governance, as well as evidence that various entities participate in the promotion of environmental policy. However, the judgment made by actors' centrality ranking involves China remaining a government-oriented top-down policy country and that its genuine environmental governance has been underway and is still in its early stages.

\subsection{The Result of Network Analysis}

After text mining, this study conducted network analysis on the top 30 words based on the frequency and centrality in each period. This process enabled us to grasp the network type and cluster structure between words. Table 2 shows the result of CONCOR analysis.

Table 2. CONCOR analysis results for each period.

\begin{tabular}{|c|c|c|c|c|}
\hline Subject Words & \multicolumn{4}{|c|}{ Environmental Policy } \\
\hline Collecting & \multicolumn{4}{|c|}{ Baidu (Portal)/Weibo (Blog)/WeChat (SNS) } \\
\hline Period & 10th FYP & 11th FYP & 12th FYP & 13th FYP \\
\hline $\begin{array}{l}\text { Number of } \\
\text { clusters }\end{array}$ & 8 & 6 & 7 & 6 \\
\hline Average degree & 7.733 & 22.200 & 28.067 & 27.867 \\
\hline $\begin{array}{l}\text { Average clustering } \\
\text { coefficient }\end{array}$ & 2.117 & 7.567 & 24.363 & 22.968 \\
\hline Major hub nodes & $\mathrm{PC} / \mathrm{EP} / \mathrm{EI}$ & \multicolumn{2}{|c|}{ CG/Social/EL/Enterprise CG/EL/ET/RA } & $\mathrm{EL} / \mathrm{BEP} / \mathrm{ET}$ \\
\hline $\begin{array}{l}\text { Significant } \\
\text { keywords in the } \\
\text { major clusters } \\
\text { (cluster } \\
\text { coefficient) }\end{array}$ & $\begin{array}{c}\text { Author } \\
\text { (6.000)/Chemical } \\
\text { engineering } \\
\text { (5.667)/PC } \\
(4.533) / \mathrm{DEP} \\
(4.000) / \text { Tax policy } \\
(3.600)\end{array}$ & $\begin{array}{c}\text { Solution (9.978)/AD } \\
(9.416) / \text { Institution } \\
(9.029) / \mathrm{ET} \\
(8.629) / \mathrm{LG}(8.386)\end{array}$ & $\begin{array}{l}\text { USA (28.180)/DEP } \\
(26.986) / \text { Engineering } \\
(26.581) / \text { Global } \\
(26.554) / L G(25.569)\end{array}$ & $\begin{array}{c}\text { RA }(25.865) / \mathrm{EP} \\
(25.591) / \text { Information } \\
\text { (25.111)/Nationwide } \\
\text { (24.801)/Administrative } \\
\text { procedure }(24.400)\end{array}$ \\
\hline
\end{tabular}

Note: AD = Administrative Department; BEP = Bureau of Environmental Protection; CG = Central Government; $\mathrm{DEP}=$ Department of Environmental Protection; EI = Environment Industry; EL = Environmental Law; EP = Environmental Project; ET = Environmental Technology; LG = Local Government; PC = Publishing Company; RA = Resource Allocation. 
First, the results show that there are eight clusters in the 10th FYP, six clusters in the 11th FYP, seven clusters in the 12th FYP, and six clusters in the 13th FYP. The average degree refers to the average value of the sum of the in-degree and out-degree of the nodes as well as serving as a measure for determining the connectivity between certain words. The average degree in the period of the 13th FYP was 7.733, which means that no strong expression of environmental policy issues was socially made. However, since the period of the 11th FYP, it has been 22.2, 28.067 for the 12th FYP, and 27.867 for the 13th FYP, indicating that various issues related to the environmental policy have been actively discussed. The average clustering coefficient is a measure of the degree to which nodes in a network are grouped together. The clustering coefficient has also increased to 7.567 in the 11th FYP, 24.363 in the 12th FYP, and 22.968 in the 13th FYP. This is despite the low coefficient, 2.117, in the 10th FYP. It can be interpreted that the cohesion of the nodes has been strengthened. In particular, the highest values of the average degree and the average clustering coefficient during the 12th FYP stemmed from the fact that the role of China's responsibility about global environmental issues has been emphasized and various environmental policy discussions have been held in China. Focusing on the hub node, the major node of China's environmental policy promotion during the 10th FYP is the role of media, environmental projects, and the environmental industry, which is directly targeted by environmental policies.

The 11th FYP exhibits the emergence of early forms of environmental governance, where the government, central government, society, and the enterprises devote themselves to promoting environmental policies together, and the reformation of the environmental law to establish the institutional framework. During the 12th FYP, the resource allocation and the legal and institutional regulations of the central government were the important nodes in environmental policies because of the influence of the economic and industrial restructuring policy of China's government. Environmental technology has been continuously emphasized between the 12th and the 13th FYPs. In the period of the 13th FYP, efforts went into securing the administrative department pursuing environmental policies, as well as providing procedural justification of the environmental policy with a legal basis. In terms of keywords occupying important positions in clustering, it is worth noting the chemical engineering industry and the tax policy during the 10th FYP. This meant that environmental policies focused on chemical field-related regulations and mainly tax-regulated policies during the same period. It shows that efforts were made to develop policy alternatives for environmental protection at the local government level during the 11th FYP. The US, which refers to China's accountability for global environmental issues, was found to be an important node within clustering during the 12th FYP. Finally, during the 13th FYP, environmental policies have been carried out at the national level, which indicates that the implementation is relevant to the efficient allocation of resources through China's economic and industrial restructuring. In particular, it can be inferred that the accessibility of related information has been facilitated and that the environment-related projects are underway (see Appendix B, Figures A1-A4).

\subsection{The Result of Continuous Core-Periphery Analysis}

The matrix dataset for the top 10 actors and policy keywords was constructed for each period after refining the words based on the text big data collected with the keyword, "environmental policy". Next, the coreness scores of the datasets were measured, and the results are shown in Tables 3 and 4. 
Table 3. The result of coreness score analysis for policy actors by period.

\begin{tabular}{ccccccccc}
\hline \multirow{2}{*}{ Rank } & \multicolumn{2}{c}{ 10th FYP } & \multicolumn{2}{c}{ 11th FYP } & \multicolumn{2}{c}{ 12th FYP } & \multicolumn{2}{c}{ 13th FYP } \\
\cline { 2 - 8 } & Words & Corene. & Words & Corene. & Words & Corene. & Words & Corene. \\
\hline $\mathbf{1}$ & PC & 0.701 & Media & 0.808 & BEP & 0.988 & BEP & 0.972 \\
$\mathbf{2}$ & Author & 0.656 & DEP & 0.492 & Institution & 0.006 & Institution & 0.158 \\
$\mathbf{3}$ & EI & 0.275 & Enterprise & 0.307 & AD & 0.003 & AD & 0.151 \\
$\mathbf{4}$ & EA & 0.052 & BEP & 0.103 & Enterprise & 0.001 & Social & 0.048 \\
$\mathbf{5}$ & DEP & 0.040 & Institution & 0.019 & Social & 0.001 & CG & 0.045 \\
$\mathbf{6}$ & CG & 0.036 & Social & 0.010 & DEP & 0.001 & GI & 0.043 \\
$\mathbf{7}$ & Social & 0.021 & SCC & 0.007 & Market & 0.001 & EI & 0.028 \\
$\mathbf{8}$ & LG & 0.007 & CG & 0.006 & EI & 0.001 & Enterprise & 0.026 \\
$\mathbf{9}$ & Public & 0.004 & EI & 0.004 & CG & 0.001 & DEP & 0.014 \\
$\mathbf{1 0}$ & Media & 0.001 & LG & 0.003 & LG & 0.001 & LG & 0.001 \\
\hline
\end{tabular}

Note: AD = Administrative Department; BEP = Bureau of Environmental Protection; CG = Central Government; $\mathrm{DEP}=$ Department of Environmental Protection; EA = Environmental Administrator; EI = Environment Industry; GI = Government-affiliated Institutions; LG = Local Government; PC = Publishing Company; SCC = State Council of China.

Table 4. The result of coreness score analysis for policy keywords by period.

\begin{tabular}{|c|c|c|c|c|c|c|c|c|}
\hline Rank & \multicolumn{2}{|l|}{ 10th FYP } & \multicolumn{2}{|c|}{ 11th FYP } & \multicolumn{2}{|c|}{ 12th FYP } & \multicolumn{2}{|c|}{ 13th FYP } \\
\hline 1 & RA & 0.706 & RA & 0.852 & ES & 0.909 & Economy & 0.495 \\
\hline 3 & Soil environment & 0.056 & Eco-friendly & 0.224 & ET & 0.170 & IS & 0.429 \\
\hline 4 & EL & 0.014 & IS & 0.151 & Economy & 0.111 & Responsibility & 0.292 \\
\hline 5 & $\mathrm{EP}$ & 0.013 & $\mathrm{EP}$ & 0.064 & IS & 0.045 & Eco-friendly & 0.268 \\
\hline 8 & Trade & 0.001 & EE & 0.006 & EP & 0.008 & Network & 0.221 \\
\hline 9 & Chemical engineering & 0.001 & ES & 0.002 & RA & 0.008 & EE & 0.178 \\
\hline 10 & Environmental economy & 0.001 & Economy & 0.001 & Regime & 0.001 & $\mathrm{EP}$ & 0.142 \\
\hline
\end{tabular}

Note: EE = Ecological Environment; EL = Environmental Law; EP = Environmental Project; ES = Environmental

Standard; ET = Environmental Technology; IS = Industrial Structure; RA = Resource Allocation.

First, the result of environmental policy actors demonstrates that the role of media was relatively emphasized in the periods of the 10th and 11th FYPs and that the roles of the government agencies and environmental departments were important in the periods of the 12th and 13th FYPs. In particular, the investigation of the changes in the roles of society and enterprise from the perspective of promoting environmental governance policies reveals that the rank of society's role gradually rises from seventh to fourth along with the period change. The role of private enterprises occupied a relatively high position, ranked third and fourth and 4th, in the periods of the 11th and 12th FYPs, respectively, while in the period of the 13th FYP, the role of private enterprise decreased because of the relatively strengthened role of the government.

By examining the changes in policy keywords shown in Table 4, it is notable that the role of resource allocation was emphasized more than anything else during the period of the 10th and 11th FYPs. The results also suggest that the main environmental policy targets for each period have evolved as follows: The regulation-oriented taxation policy during the 10th FYP; the policy for environmental technology development during the 11th FYP; the establishment and standardization of laws and standards during the 12th FYP; and the environmental policy emphasizing environmental friendliness and accountability during the 13th FYP.

Next, when performing multi-dimensional scaling (MDS), a two-dimensional analysis uses the matrix generated by multiplying each node's coreness score; the node at the center of the network is placed at the center of the graph, while the nodes in the network's periphery are placed outside the center. This allows us to observe not only which nodes are the center or periphery nodes but also whether the center nodes as a series are near the center's boundary or near the periphery from the 
continuum. Figures 2 and 3 demonstrate the MDS analysis results for the top 10 actors and policy keywords for each period.
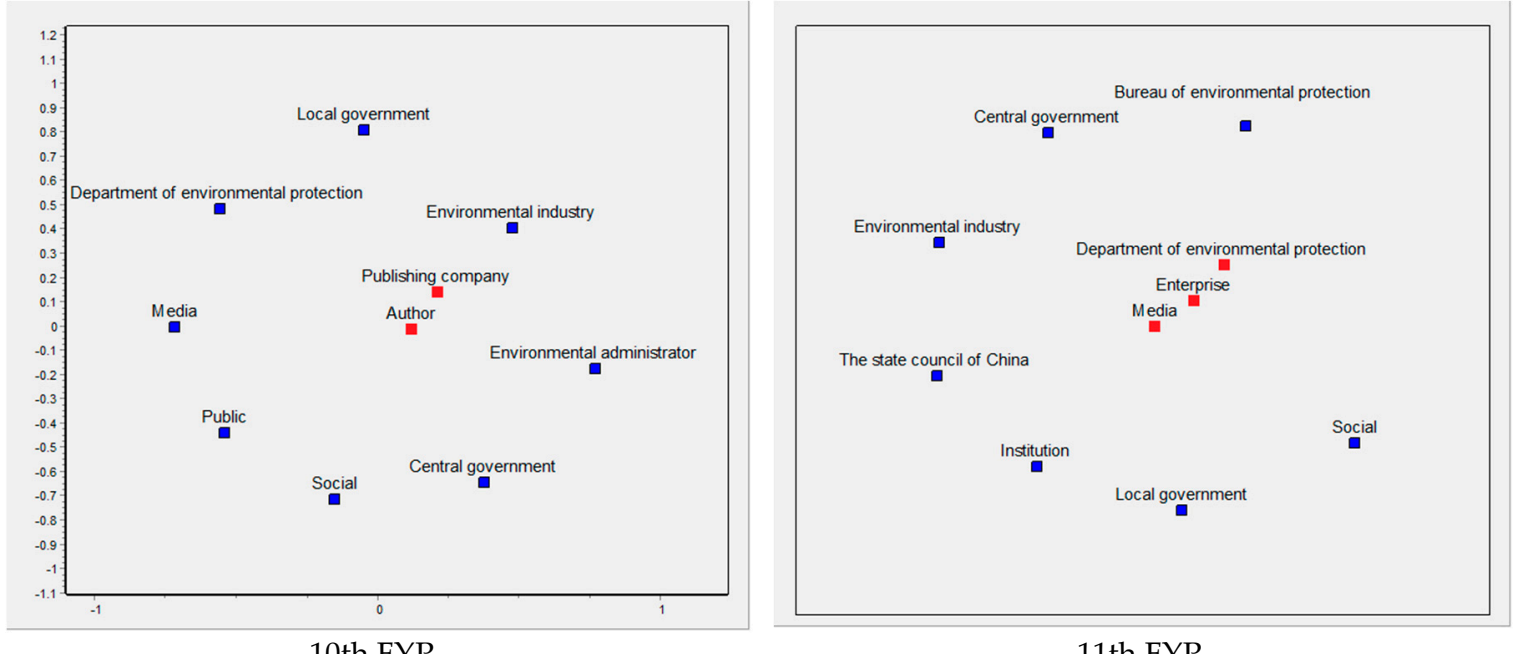

10th FYP

11th FYP

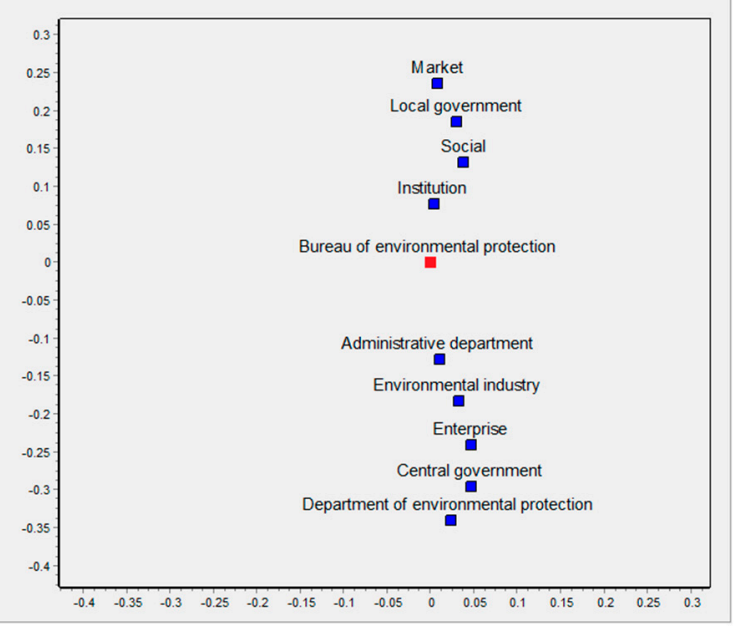

12th FYP

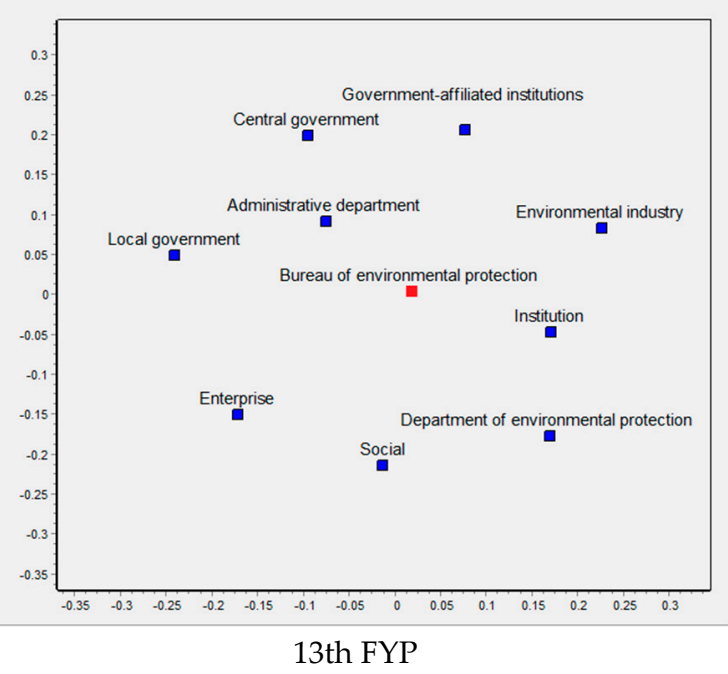

Figure 2. MDS analysis results for the top 10 actors for each period. 


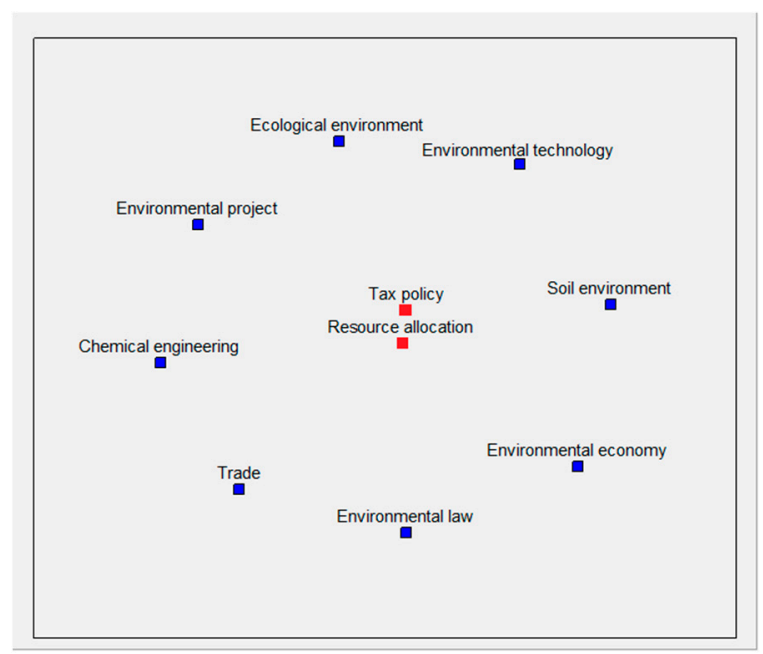

10th FYP

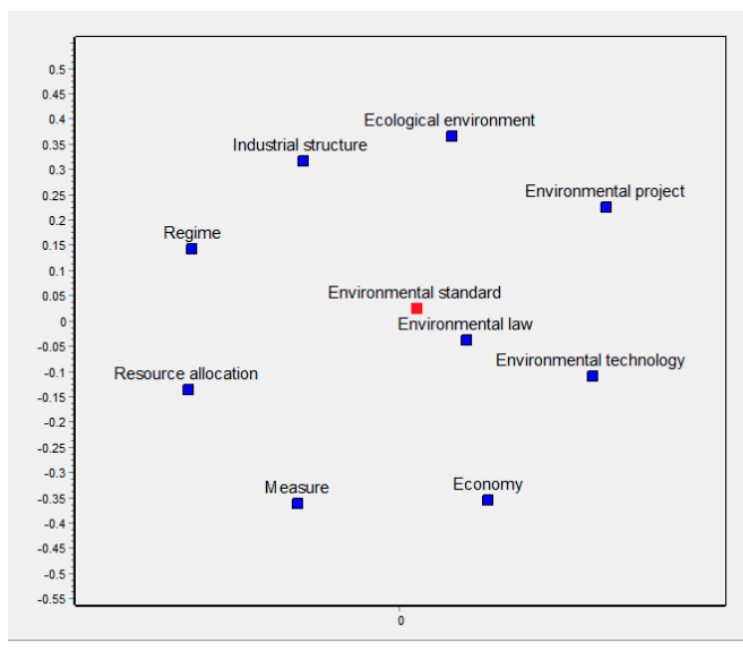

12th FYP

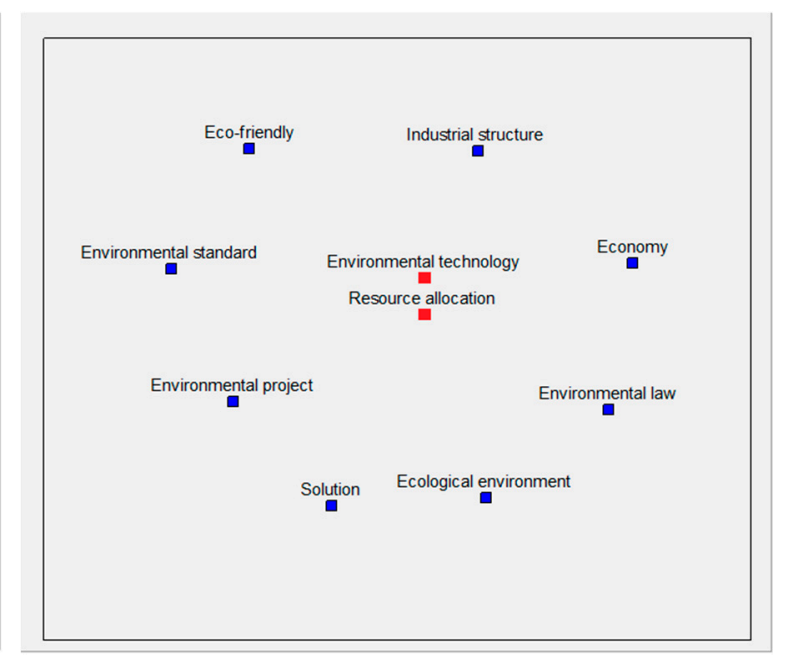

11th FYP

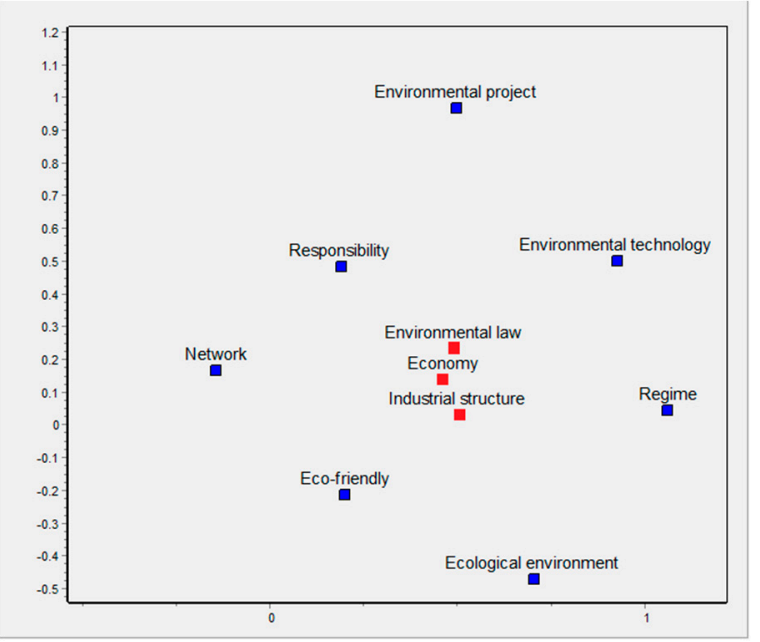

13th FYP

Figure 3. MDS analysis results for the top 10 policy keywords for each period.

First, if we examine the actors leading the policy and playing a major role in China's environmental policy in Figure 2, two actors, the publishing company and author, are located at the center of the period for the 10th FYP, and three actors, department of environmental protection, enterprise, and media, are at the center. In particular, the governance type, where governments, enterprises, and media simultaneously influence policies, is at the center of environmental policies for the period of the 11th FYP. On the other hand, the periods of the 12th and 13th FYPs show the bureau of environmental protection as the major actor, suggesting that the environmental policy being pursued is centered on the central government again. In terms of environmental governance, this reflects the fact that the authority wielded by the private sectors and environmental NGOs is still insignificant when compared with the power of the central government or that they remain passive about raising social issues. Another contributor is that various participants in China's environmental policy are not completely free from government and agencies in financial matters [18].

Next, according to the result of the core-periphery analysis of major policy keywords related to environmental policies in each period, resource allocation is located at the center during the periods of the 10th and 11th FYPs, which implies that it is the main keyword of environmental policy promotion of the time. These are the periods when China regarded rapid economic growth as a more important task than environmental protection and strived to improve economic growth efficiency through apposite 
resource allocation. Thus, China indirectly promoted environmental protection policies by way of imposing taxes and supporting environmental technologies. In the period of the 12th FYP, the standard appears to be the word at the core of the environmental policy promotion. The result indicates that the international community emphasized China's responsibility for environmental protection during the same period; hence, the establishment and coordination of environmental standards in China has become a major policy promotion task. During the 13th FYP, economic and environmental legislation and industry restructuring were at the center, leading environmental issues.

This was the time when China began to concentrate on qualitative growth, namely, harmonious and rational growth, rather than quantitative growth, by adjusting its rapid economic growth goals. In terms of environmental policy, it can be interpreted that China strives to solve problems by establishing stable environment-related systems and restructuring the environmental pollution-creating industry as a fundamental solution for environmental issues at the same time. In terms of environmental governance, however, upon observing the actors pursuing environmental policies with industrial restructuring taking place under the lead of the government rather than economic logic, it is reasonable to assume that the government might wield its influence over policies, markets, and industry at any time in the future. Since China is a country with strong policy implementation capability, it can exercise strict monitoring and regulation over environmental issues through centralized policy implementation. However, since environmental issues require various stakeholders, social influences, and long-term commitments, it is significant to solve the issues through governance and in a gradual way in which various entities rather than an individual cooperate.

\section{Discussion}

This study analyzed major actors, their roles, and policy keywords for China's environmental policies for each period. In the phase when governance-based problem-solving was considered to be an effective way of promoting environmental policies due to the peculiarities of environmental issues, discussions were held to examine the effectiveness of environmental policies in terms of environmental governance, the types of future policies to be promoted in China, a centralized system of government, and powerful policy implementation at the center of global environmental issues. To this end, this study constructed metrics for the words of centrality criteria through the process of refining text big data collected in Chinese environmental policy as the main word. The analysis was conducted to examine the major actors and policy keywords in China's environmental policies through a network and core-periphery analyses of the actors and policy keywords for the same metrics. The conclusions drawn are as follows:

The text mining demonstrating the changes in the top 10 actors and policy keywords by the centrality standard indicates that the government still has a strong impact on environmental policies in China. There are at least four government-related actors out of the 10 (e.g., central/local government, environmental administrator, administrative department, the state council, department of environmental protection, and bureau of environmental protection) derived from all periods, and they have been shown to have strong centrality in general. There were certainly the words social, public, enterprise, and institution in the aspects of environmental governance, while these very words failed to be at the center of MDS analysis for the actors. This result shows that environmental governance and network are still at an early stage and that the Chinese government's strong power lies in its environmental policy.

Environmental governance emphasizes building cooperative governance with various members outside of the bureaucracy because bureaucratic groups with strong control, such as government or administrative agencies, have limited control over environmental issues through internal coordination and control. Therefore, any actors participating in governance should not be excluded from their unfamiliarity with the ways in which the administration and bureaucrats promote policies. It is also about the government's capability to adequately understand which groups or organizations have related resources and solutions to various environmental issues.

China's environmental policy nominally expresses cooperative policy promotion based on the involvement and communication of many related stakeholders under governance principles. 
However, this study's results revealed that the groups of important actors and leaders guiding China's environmental policies were "led by the government". China's actual policy implementation of environmental issues work toward government-led solutions rather than governance solutions just as China has achieved rapid economic growth through the government-led economic development model. From a short-term perspective, government-led environmental policies appear to be certainly effective; on the other hand, performance from a long-term perspective requires governance-based policy promotion that solves problems in cooperation with various entities based on strong networks related to environmental issues.

In order for China to solve environmental problems and achieve long-term sustainable development, a hot topic of global environmental problems, governance relations, and cooperation among the following environmental policy actors are needed.

First, it is necessary to clarify the boundary of responsibility and authority in the relationship between the central government and local government. In terms of environmental governance, it is necessary to separate policymaking and implementation functions conducted by central government agencies because environmental policy tends to focus on results rather than administrative procedures. Alternative possibilities for the separations are that the central government agencies take charge of the responsibility of policy decision-making to concentrate on long-term policy planning and coordination and that policy execution functions are hived off into external executive agencies. Such a phenomenon has implications for the reorientation of policy establishment and implementation in China, where the central government agencies include policy decision-making and implementation functions.

For example, there have been cases in which the $\mathrm{SO} 2$ control equipment required by many local businesses had to be shut down because its power consumption for operation conflicts with the policy on climate change emphasized by the central government. To overcome these side effects, it is necessary for the central government to establish macro-level regulatory targets that concurrently adopt environmental, energy, and economic growth, and for the local governments to implement detailed strategies and policy enforcement to achieve these goals. Particularly in this process, a governance attitude is required to secure monitoring function through corporate autonomy and citizen participation [54] and for the whole society to make an effort for the improvement of the environment.

However, communication and cooperation for environmental policies are needed between local governments. For example, Dongjiang Lake in Hunan Province is divided between and managed by four local governments. Their different management systems for unpolluted areas (tourism resources) and polluted areas (coal mining) were primary reasons hindering water pollution resolution [33]. Thus, it is more efficient for a complete ecosystem, such as lakes, rivers, or wetlands, to be managed by the leader of one local government organization rather than by different ministries and local governments. In this process, the attitude to promote cooperation and communication would be required between local governments and driving strategies for environmental governance through cooperation would be effective.

Second, it is crucial for the relationship between government and private enterprises to adopt positive attitudes toward corporate governance to coordinate interests with each other gradually. Under the system where the government has taken a leading role in establishing a policy reflecting environmental solutions and the system to realize it efficiently and effectively in society, the intermediate organizations existing between the government and enterprises tend to act in government service according to the preference of the government sector rather than the members of the enterprise sector. However, it is important for enterprises to establish a partnership with the government to solve environmental issues in the manner of environmental governance. This is because the enterprises can act as practical participants in solving environmental issues and their prompt and independent activities can address environmental issues more positively to solve them. In this process, the government should assume the role of establishing standards of macro-environmental policies, such as environmental standardization, a legal framework for environmental issues, and not shirking responsibility for solving environmental issues faced by enterprises. Moreover, the government has a responsibility to support 
SMEs with relatively poor human and material resources and to perform study and development investment as the government actively enterprise solidarity in areas where their increased cooperation is needed in preparation for new forms of market structure.

For example, although it is desirable to impose a high carbon tax to effectively operate the Emission Trading Scheme, this scheme produces virtually little effect on environmental improvement due to the strong rebound of enterprises in China [69]. In the long-term perspective, however, enterprises need to actively cooperate or act as leading policy partners to improve their social images and generate profits. Governments and enterprises need to address issues related to the relocation of polluting enterprises through flexible governance. For example, carbon emissions from Beijing and Tianjin increased by 33\%, from 60 to 80 million tons, and by $46 \%$, from 56 to 82 million tons, between 1997 and 2015. Conversely, the surrounding area, Shandong province, recorded 1.05 billion tons in 2015 , surging by $300 \%$ from 260 million tons in 1997. It was the result of the relocation of enterprises in the economic and administrative districts with superiority to the outside or the surrounding areas. Thus, the promotion of environmental governance requires the reduction of some government functions; however, the creation of a new government functions simultaneously. This demonstrates the need for a rational decision-making mechanism between the government and enterprise and the significance of establishing a harmonious network relationship.

Third, the relationship between the government and environmental organizations shall become a communication network that fulfills mutual support and positive monitoring. The government can make ultimate contributions to environmental conservation by seeking rules and conditions for reestablishing the role and status of environmental organizations to induce cooperative behavior among social components. In particular, the government should precede institutional and financial support for environmental organizations to play a role in policy diffusion and healthy criticism. The government should shift away from the previous approach of having controlled and suppressed environmental organizations because of its assumption regarding them as being obstacles for its growth policy and make overtures in the direction of recognizing environmental organizations as an object of cooperation for solving environmental issues. In other words, it is crucial to forming a mechanism that enables environmental organizations to complement the weakness of the government, as environmental issues become a critical task to be solved by the country. Furthermore, achieving environmental governance through a network of the government and environmental organizations results in the formation and diffusion of environmental ethics. Therefore, problems related to environmental issues, such as Nimbyism, collectivism, and individual egoism, can be solved to a considerable extent. It is because environmental organizations backed by self-awareness and the voluntary participation of citizens rather than government agencies can play a leading role in problem-solving. Thus, approximately 1000 environmental organizations in China should participate in the policy-making process through a network with government decision-makers and experts, and lead to establishing links and ties with civil society. By doing so, the organizations need to derive a shift in the negative perception of government environmental groups and adhere to the role of building bridges between citizens and the government.

Finally, it requires the public's concern for the environment and positive willingness to solve issues, as well as an organic cooperation network of the aforementioned environmental policy actors. Perception changes in solving environmental issues are important as public sympathy and concern for the environment have become the premise for sustainable development that goes beyond the leading issues of some organizations and institutions and those recognized by many individuals. In this process, citizens should have direct access to important policymaking processes, stakeholder groups, and information, and they should be able to monitor policy decision-making processes by utilizing the acquired knowledge [70]. In this sense, the free flow of information should be built on the foundation of transparency. Moreover, institutional mechanisms and processes must converge into a fair legal system, and the implementation of law must be fair. This means that the rule of law and responsiveness to the law must be complete. Leaders who lead the country along with the public should also have a constant concern for environmental issues and policies, as well as responsibilities for 
the resolutions. Leaders need a strategic vision to share a long-term perspective on fine society, good governance, and the factors required for that development. In this process, the authority should secure its legitimacy under clear legal and institutional grounds, and specific decisions should be legitimate through accepted standards, processes, and procedures. This should lead to the proliferation of consciousness that resources should be used and managed so that generations can ultimately optimize the well-being of the people without sacrificing the future of the people.

Heightened awareness of environmental issues by Chinese citizens has led to environmental issues and urged governments to implement more environment-friendly policies [54,71]. Although this social issue does not cause a fundamental change in government policies or challenge the government, the heightened awareness can lead to a positive change to enhance future generations' interest in environmental policies. In particular, citizens should provide the government with help to secure its accountability and to decide policy priority orders through various SNS platforms, participate in hearings for environmental impact assessments, and serve as surveillants for environmental policy enforcement of local governments through media.

\section{Conclusions}

This study verified the actors and keywords related to China's environmental policies through text mining and network analysis. In particular, this study analyzed actors and keywords leading changes in the policies by each period of China's five-year plan, and further examined what the major actors and keywords are among them. The results of this study are as follows. First, the government, particularly the central government, has a strong centrality as a major driving force of China's environmental policies. This result indicates that China's environmental governance has been socially publicized while governance has stagnated at an early stage. Second, China's environmental policy has shifted its phases from the initial regulatory focus to the improvement of environmental criteria and regulations. This shift is an indispensable factor for ensuring the effectiveness of environmental governance, which indicates that China is in the transition period to establish a system that meets its development situation. Third, the central government's resolve exerts a strong impact on China's core leading environmental policies. Furthermore, the power and factors for sustainable economic growth and environmental policies are linked and reflected in the regulations.

This study has the following limitations despite the meaningful results obtained from sequential temporal analysis on environmental policy actors and policy keywords in China. First, actors and policy keywords were derived by selecting one country's environmental policy as the main word despite the diversity of environmental policy areas. This means that it is not possible to accommodate all the variations of the results caused by detailed policies concerning matters, including water, soil, atmosphere, waste resources, related interest groups, and network structure, are different. In the future, a careful analysis by selecting detailed policy keywords as the subject word is in order. In the process of discussing environmental issues through the policy case, we focused on the air pollution and water pollution areas emphasized in China at present. Given the comprehensive nature of environmental issues, there is a need to expand to sections on waste management, soil contamination, and climate change, and will be covered in future studies. Second, it is the limit of data collection. The text data used in this study were collected from the main portal websites in China. However, this limitation could not be completely ruled out because of the political system characteristics that China exerts its leadership under a strong socialist system and because internationally and socially sensitive issues are tacitly controlled by media. Therefore, the study could not exclude the possibility that the text big data collected were post-censored data. Third, the analysis results and policy suggestions of this study may not be generalizable. This is because China's political and economic characteristics are reflected, and the recognition of environmental issues depends on the economic level and the political system of the country. Such problems are required to be complemented and studies conducted according to the characteristics of each country in the future. 
Author Contributions: D.Z. and F.F. conducted the investigation, collected the data, performed the analysis and original draft preparation. S.D.P. led the research activities, developed the research framework, and conducted the review and editing of the article.

Funding: This research received no external funding.

Conflicts of Interest: The authors declare no conflict of interest.

\section{Appendix A}

In general, centrality refers to the degree to which a particular node is centered within a network. Depending on the attributes of the relationship, centrality can be interpreted in various ways (e.g., degree, closeness, and betweenness) [72]. In the present study, the degree of centrality is measured by quantifying the degree to which a node is centered and by how much it is related to the other nodes. In this case, centrality is expressed as follows:

$$
C_{D}^{\prime}\left(N_{i}\right)=\frac{C_{D}\left(N_{i}\right)}{g-1}
$$

where $C_{D}^{\prime}\left(N_{i}\right)$ denotes the degree of centrality of a node $i$, in which the value of $C_{D}\left(N_{i}\right)$ depends on the size of the network. $C_{D}\left(N_{i}\right)$, in this case, denotes the degree of centrality of a node $i$, calculated by $\sum_{j=1}^{g} x_{i j}, i \neq j$. Here, $\sum_{j=1}^{g} x_{i j}$ is the number of connections that node $i$ has with the other nodes, $g$ is the number of nodes, and $x_{i j}$ denotes whether there is a connection between the node $i$ and the other nodes. Moreover, $g-1: x_{i j}=1$ when a connection exists; otherwise, $x_{i j}=0$.

Next, the equation for constructing the correlation matrix used in this analysis is expressed as follows [67]:

$$
r_{i j}=\frac{\sum_{r=1}^{2 R} \sum_{k=1}^{g}\left(x_{i k r}-\overline{x_{i}}\right)\left(x_{j k r}-\overline{x_{j .}}\right)}{\sqrt{\sum_{r=1}^{2 R} \sum_{k=1}^{g}\left(x_{i k r}-\overline{x_{i .}}\right)^{2}} \sqrt{\sum_{r=1}^{2 R} \sum_{k=1}^{g}\left(x_{j k r}-\overline{x_{k}}\right)^{2}}}, i \neq j \neq k,
$$

where $r_{i j}, R, g$, and $x . . r$ represent the correlation coefficient between factors $\mathrm{i}$ and $\mathrm{j}$, the number of relationship types, the number of nodes, and the relationship strength in relation type r, respectively.

The core-periphery structure refers to a network structure that is composed of two actor layers. First, there is the highly dense core actor layer, and then, there is the peripheral actor layer, which is loosely coupled to the core layer and not well connected within itself [68-73]. This method is an evolutionary model that has overcome the limitations of a discrete core-periphery model for simplifying the ideal block structure by dichotomically allocating nodes to either the core node or the periphery nodes [68]. The continuous core-periphery analysis model explores the core-periphery structure, which is based on the degree of proximity of the nodes to the network core. The degree of proximity of the nodes to the core is called the coreness score, which measures the score maximizing the fit between the actual data matrix and the ideal core-periphery matrix, and ideal core-periphery structures are explored based on the results [74]:

$$
\Delta=c c^{T} \text {. }
$$

Here, the $\Delta$ is an ideal core-periphery matrix; $\mathrm{c}$ is a coreness score vector; and $\mathrm{cT}$ is a row vector transposed by vector $\mathrm{c}$. The $(\mathrm{i}, \mathrm{j})$ cell value of the matrix, $\Delta$, is calculated by multiplying ci, the coreness score of node $i$; and cj, the coreness score of node $j$. In addition, the coreness score vector, $c$, is determined for the ideal core-periphery matrix, $\Delta$, to be as close as possible to the actual data matrix. Such proximity, fitness in other words, is generally measured using correlation coefficients. Core blocks and periphery blocks are determined on the basis of a correlation coefficient of the calculated coreness score and the ideal coreness score, and the correlation coefficient is repeatedly calculated while varying the central block size from 1 to $(n-1)$. The (n-1) correlation coefficients calculated by such a method can be used as a measure showing how close the network data is to the core-periphery structure, and the block segment showing the largest value qualify is selected as the optimal core-periphery structure [67]. 


\section{Appendix B}

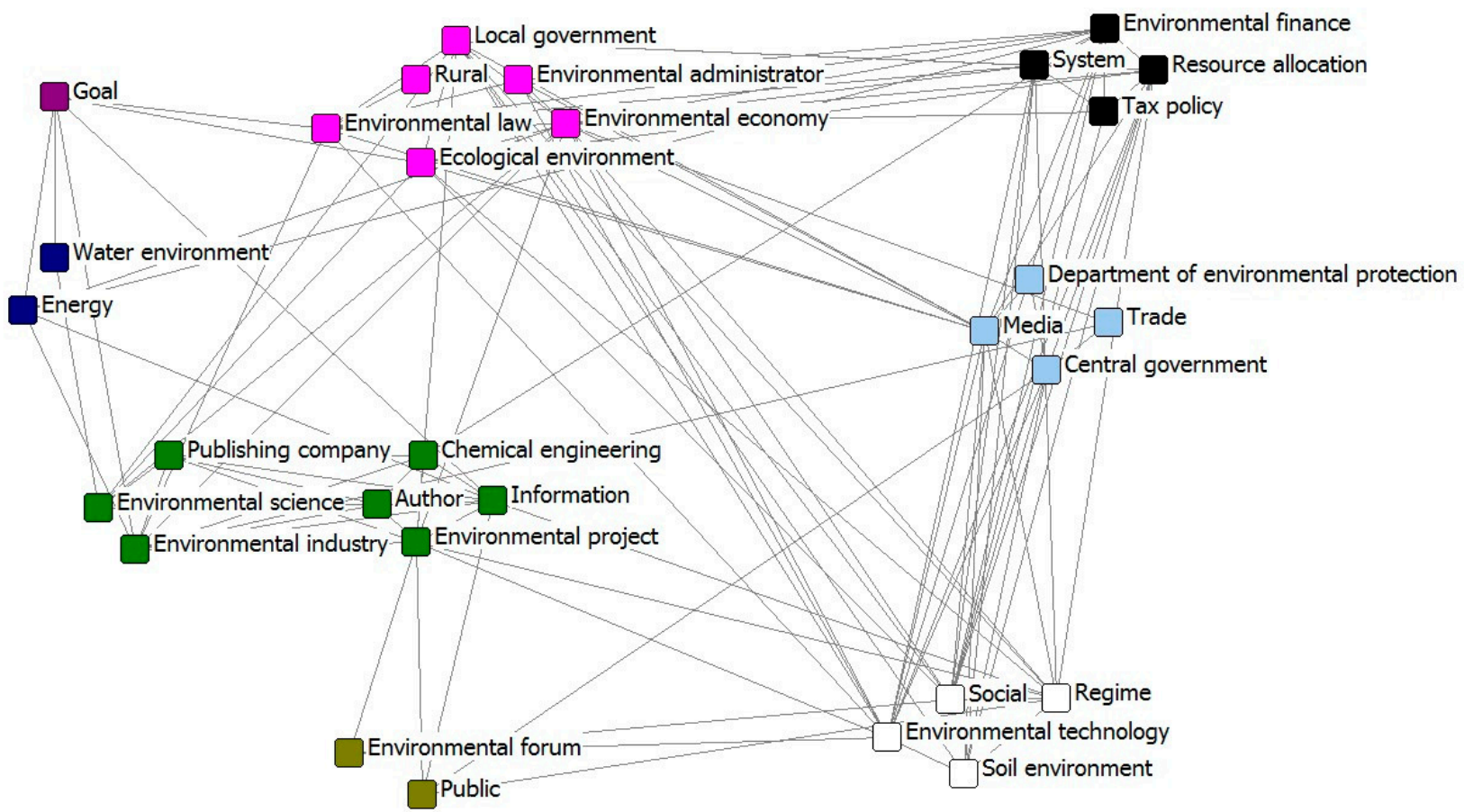

Figure A1. The results of CONCOR analysis by 10.5 FYP. 


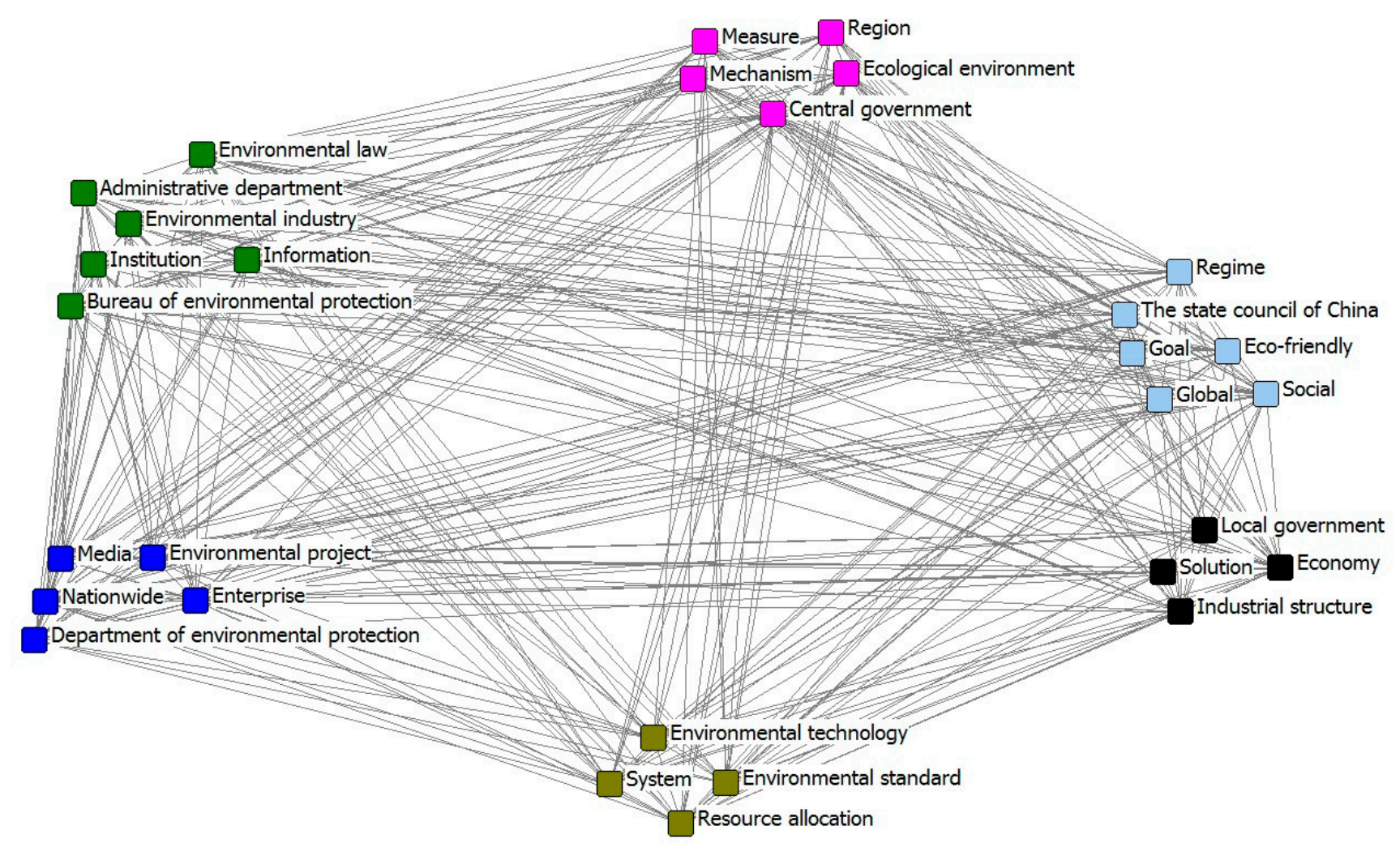

Figure A2. The results of CONCOR analysis by 11.5 FYP. 


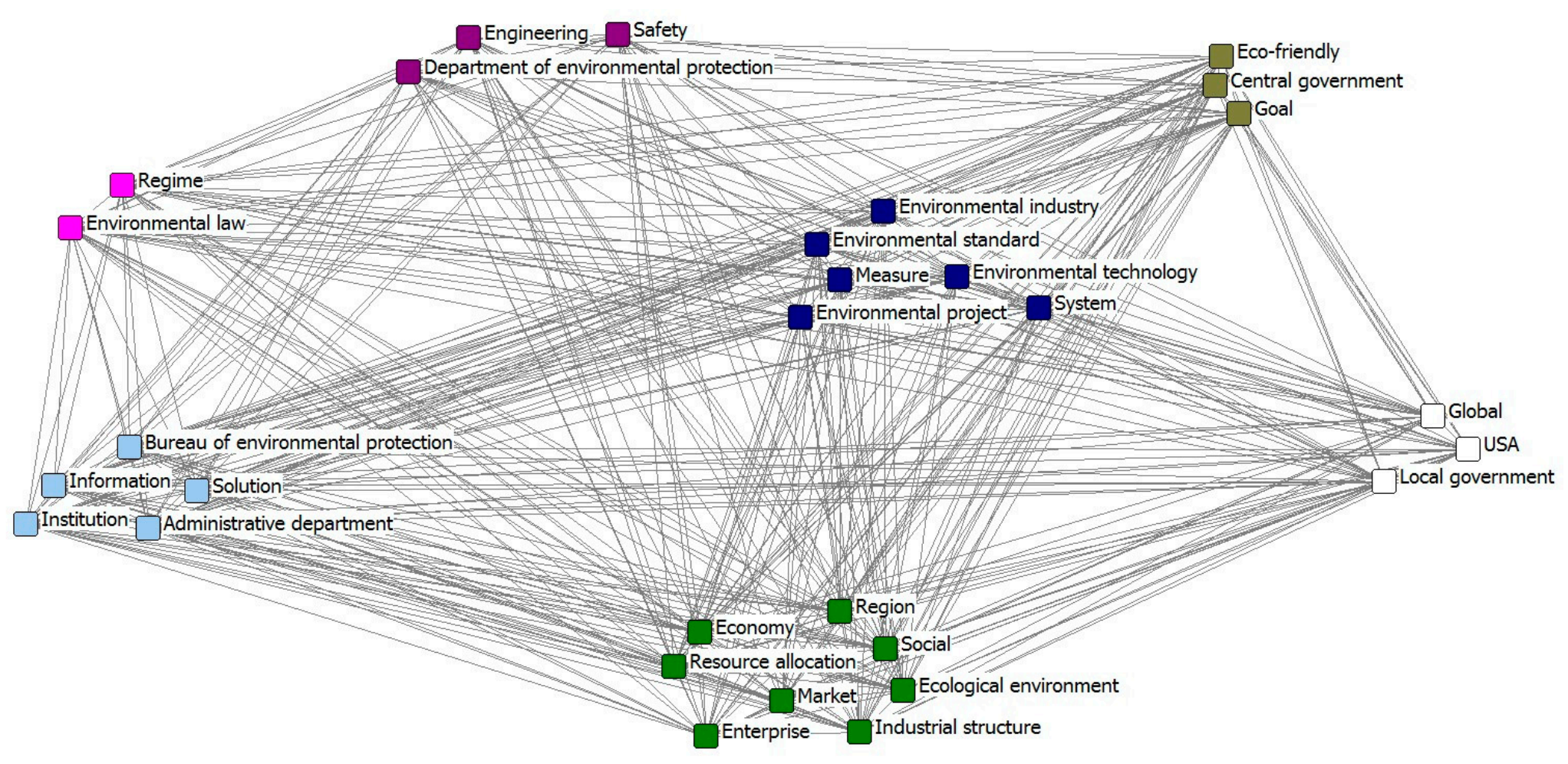

Figure A3. The results of CONCOR analysis by 12.5 FYP. 


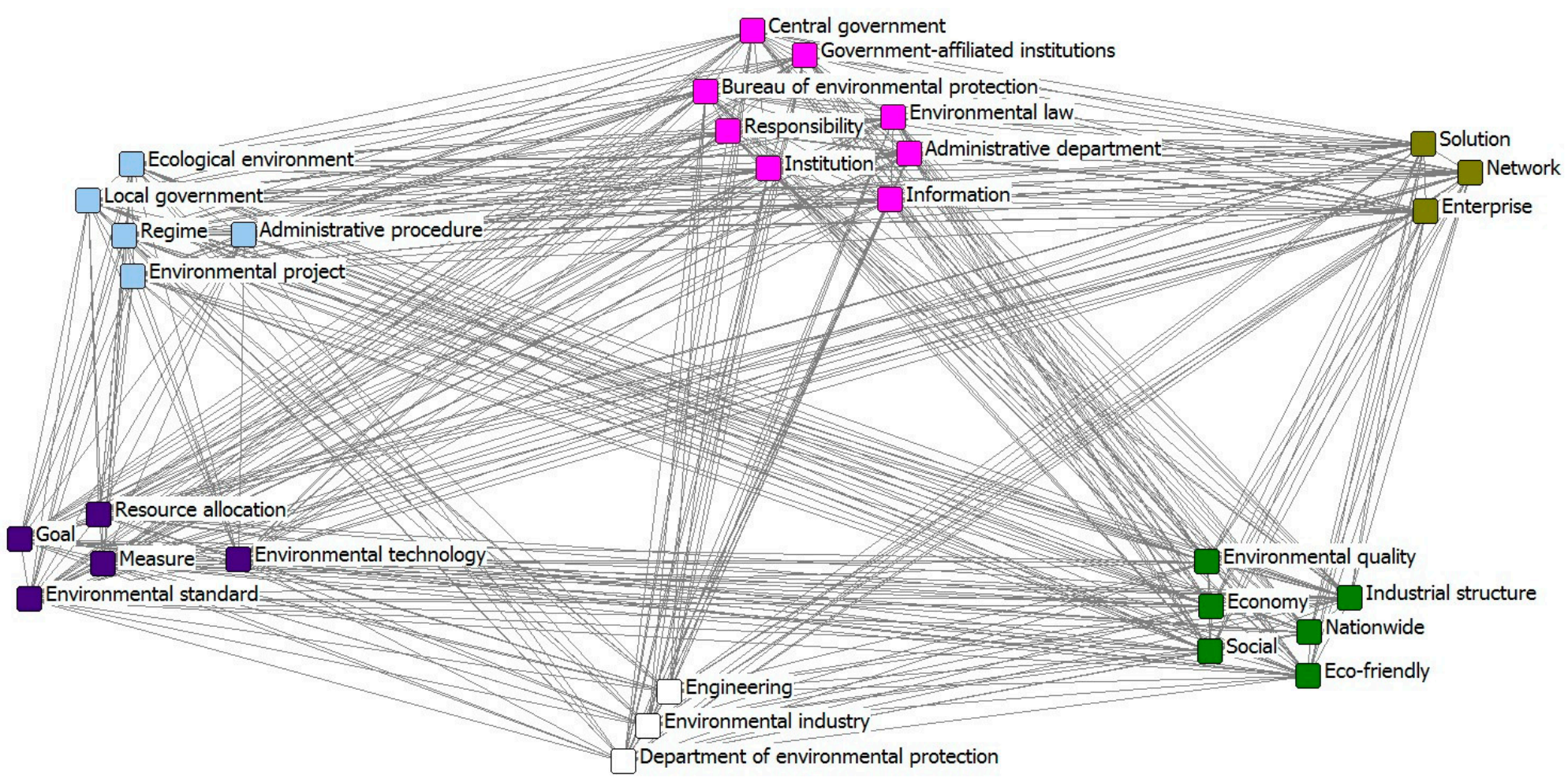

Figure A4. The results of CONCOR analysis by 13.5 FYP. 


\section{References}

1. Olaussen, J.O. Environmental problems and regulation in the aquaculture industry: Insights from Norway. Mar. Policy 2018, 98, 158-163. [CrossRef]

2. Cobbinah, P.B.; Poku-Boansi, M.P.; Peprah, C. Urban environmental problems in Ghana. Environ. Dev. 2017, 23, 33-46. [CrossRef]

3. Periñán-Pascual, C.; Arcas-Túnez, F. Detecting environmentally-related problems on Twitter. Biosyst. Eng. 2019, 177, 31-48. [CrossRef]

4. Van der Molen, F. How knowledge enables governance: The coproduction of environmental governance capacity. Environ. Sci. Policy 2018, 87, 18-25. [CrossRef]

5. Prăvălie, R. Drylands extent and environmental issues: A global approach. Earth Sci. Rev. 2016, 161, $259-278$. [CrossRef]

6. Fredrickson, H.L. Towards understanding and managing sustainable complex, dynamic environmental/economic/social systems: The evolving role of the natural sciences. Encycl. Sustain. Technol. 2017, 1, 3-9.

7. Sartal, A.; Llach, J.; Vázquez, X.H.; de Castro, R. How much does lean manufacturing need environmental and information technologies. J. Manuf. Syst. 2017, 45, 260-272. [CrossRef]

8. Krumins, J.; Klavins, M.; Kalnina, L. Fen peat in environmentally friendly technologies. Energy Procedia 2018, 147, 114-120. [CrossRef]

9. Drotarova, J.; Blistanova, M. The importance and optimization of the educational process of environmental management and environmental engineering for security managers. Procedia Soc. Behav. Sci. 2015, 186, 1050-1054. [CrossRef]

10. Deniz, F.; Kepekci, R.A. Dye biosorption onto pistachio by-product: A green environmental engineering approach. J. Mol. Liq. 2016, 219, 194-200. [CrossRef]

11. Vainio, A.; Paloniemi, R. The complex role of attitudes toward science in pro-environmental consumption in the Nordic countries. Ecol. Econ. 2014, 108, 18-27. [CrossRef]

12. Sauvé, S.; Bernard, S.; Sloan, P. Environmental sciences, sustainable development and circular economy: Alternative concepts for trans-disciplinary research. Environ. Dev. 2016, 17, 48-56. [CrossRef]

13. Virapongse, A.; Brooks, S.; Metcalf, E.C.; Zedalis, M.; Gosz, J.; Kliskey, A.; Alessa, L. A social-ecological systems approach for environmental management. J. Environ. Manag. 2016, 178, 83-91. [CrossRef] [PubMed]

14. Sarkar, S. Environmental philosophy: From theory to practice. Stud. Hist. Philos. Biol. Biomed. Sci. 2014, 45, 89-91. [CrossRef] [PubMed]

15. Vatn, A. Environmental governance: From public to private. Ecol. Econ. 2018, 148, 170-177. [CrossRef]

16. Bakker, K.; Ritts, M. Smart earth: A meta-review and implications for environmental governance. Glob. Environ. Chang. 2018, 52, 201-211. [CrossRef]

17. Green, J.F. Transnational delegation in global environmental governance: When do non-state actors govern? Regul. Gov. 2018, 12, 263-276. [CrossRef]

18. Guttman, D.; Young, O.; Jing, Y.; Bramble, B.; Bu, M.; Chen, C.; Furst, K.; Hu, T.; Li, Y.; Logan, K.; et al. Environmental governance in China: Interactions between the state and nonstate actors. J. Environ. Manag. 2018, 220, 126-135. [CrossRef] [PubMed]

19. Zhang, F.; Zwolinski, P. Integrating environmental considerations into companies: A network of actions to define environmental roadmaps. J. Clean. Prod. 2017, 140, 1699-1718. [CrossRef]

20. Valentine, S.V. Kalundborg Symbiosis: Fostering progressive innovation in environmental networks. J. Clean. Prod. 2016, 118, 65-77. [CrossRef]

21. Siakwah, P. Actors, networks, and globalized assemblages: Rethinking oil, the environment and conflict in Ghana. Energy Res. Soc. Sci. 2018, 38, 68-76. [CrossRef]

22. Chen, H.Y.; Hao, Y.; Li, J.W.; Song, X.J. The impact of environmental regulation, shadow economy, and corruption on environmental quality: Theory and empirical evidence from China. J. Clean. Prod. 2018, 195, 200-214. [CrossRef]

23. Yu, X.J. Coal mining and environmental development in southwest China. Environ. Dev. 2017, 21, 77-86. [CrossRef]

24. Chang, H.J. Kicking away the Ladder: Development Strategy in Historical Perspective; Anthem Press: London, UK, 2004. 
25. Liu, L.X.; Zhang, B.; Bi, J. Reforming China's multi-level environmental governance: Lessons from the 11th Five-Year Plan. Environ. Sci. Policy 2012, 21, 106-111. [CrossRef]

26. He, G.Z.; Lu, Y.L.; Mol, A.P.J.; Beckers, T. Changes and challenges: China's environmental management in transition. Environ. Dev. 2012, 3, 25-38. [CrossRef]

27. Wu, F.S. Environmental politics in China: An issue area in review. J. Chin. Politic Sci. 2009, 14, $383-406$. [CrossRef]

28. Johnson, T.R. New opportunities, same constraints: Environmental protection and China's new development path. Politics 2008, 28, 93-102. [CrossRef]

29. Dean, J.M.; Lovely, M.E.; Wang, H. Are foreign investors attracted to weak environmental regulations? Evaluating the evidence from China. J. Dev. Econ. 2009, 90, 1-13. [CrossRef]

30. Eaton, S.; Kostka, G. Authoritarian environmentalism undermined? Local leaders' time horizons and environmental policy implementation in China. China Q. 2014, 218, 359-380. [CrossRef]

31. Kostka, G. Command without control: The case of China's environmental target system. Regul. Gov. 2016, 10, 58-74. [CrossRef]

32. $\mathrm{Mu}, \mathrm{R}$. Bounded rationality in the development trajectory of environmental target policy in China: 1971-2016. Sustainability 2018, 10, 199. [CrossRef]

33. Kostka, G.; Zhang, C. Tightening the grip: Environmental governance under Xi, Jinping. Environ. Politics 2018, 27, 769-781. [CrossRef]

34. Ahlers, A.L.; Shen, Y. Breathe easy? Local nuances of authoritarian environmentalism in China's battle against air pollution. China Q. 2018, 234, 299-319. [CrossRef]

35. Green Peace Report. 2018. Available online: https://www.greenpeace.org.cn/air-pollution-2017-city-ranking/ (accessed on 23 June 2019). (In Chinese).

36. Gilley, B. Authoritarian environmentalism and China's response to climate change. Environ. Politics 2012, 21, 287-307. [CrossRef]

37. Chen, G.C.; Lees, C. The new, green, urbanization in China: Between authoritarian environmentalism and decentralization. Chin. Political Sci. Rev. 2018, 3, 212-231. [CrossRef]

38. Shan, Y.L.; Liu, J.H.; Liu, Z.; Xu, X.W.H.; Shao, S.; Wang, P.; Guan, D.B. New provincial $\mathrm{CO}_{2}$ emission inventories in China based apparent energy consumption data and updated emission factors. Appl. Energy 2016, 184, 742-750. [CrossRef]

39. Beeson, M. Coming to terms with the authoritarian alternative: The Implications and motivations of China's environmental policies. Asia Pac. Policy Stud. 2018, 5, 34-46. [CrossRef]

40. Eriksen, S.H.; Nightingale, A.J.; Eakin, H. Reframing adaptation: The political nature of climate change adaptation. Glob. Environ. Chang. 2015, 35, 523-533. [CrossRef]

41. Delmas, M.A.; Young, O.R. Introduction: New Perspectives on Governance for Sustainable Development; Magali, A., Delmas, R., Oran, R., Eds.; Governance for the Environment: New Perspectives; Cambridge University Press: Cambridge, UK, 2009; pp. 3-11.

42. Zhang, K.M.; Wen, Z.G.; Peng, L.Y. Contemporary China's environmental policy: Formation, Characteristics and evaluation. China Popul. Resour. Environ. 2007, 2, 1-7. [CrossRef]

43. Wu, D.; Wu, C.Y. Analysis of the evolution of Chinese environmental policies since the founding of new China. J. Dalian Univ. Technol. Soc. Sci. 2006, 27, 48-52. [CrossRef]

44. Tang, J.; Xie, Y.F. Predicament analysis and transition forecast of China's environmental policy. Probe 2007, 2, 69-72. [CrossRef]

45. Wu, J.S.Y. The state of China's environmental governance after 17th party congress. East Asia 2009, 26, 265-284. [CrossRef]

46. Beyer, S. Environmental law and policy in the people's republic of China. Chin. J. Int. Law 2006, 5, $185-211$. [CrossRef]

47. Ru, J.; Ortolano, L. Development of Citizen-Organized Environmental NGOs in China. Voluntas. 2009, 20, 141-168. [CrossRef]

48. Chan, G.; Lee, P.K.; Chan, L.H. China's environmental governance: The domestic-international nexus. Third World Q. 2008, 29, 291-314. [CrossRef] 
49. Lo, K. How authoritarian is the environmental governance of China. Environ. Sci. Policy 2015, 54, 152-159. [CrossRef]

50. Wu, J.N.; Xu, M.M.; Zhang, P. The impacts of governmental performance assessment policy and citizen participation on improving environmental performance across Chinese provinces. J. Clean. Prod. 2018, 184, 227-238. [CrossRef]

51. Liu, L.; Wu, T.; Li, S.H.; Jong, M.D.; Sun, Y.H. The drivers of local environmental policy in China: An analysis of Shenzhen's environmental performance management system, 2007-2015. J. Clean. Prod. 2017, 165, 656-666. [CrossRef]

52. Panya, N.; Poboon, C.; Phoochinda, W.; Teungfung, R. The performance of the environmental management of local governments in Thailand. Kasetsart J. Soc. Sci. 2018, 39, 33-41. [CrossRef]

53. Wu, H.Y.; Guo, H.X.; Zhang, B.; Bu, M.L. Westward movement of new polluting firms in China: Pollution reduction mandates and location choice. J. Comp. Econ. 2017, 45, 119-138. [CrossRef]

54. Li, W.X.; Liu, J.Y.; Li, D.D. Getting their voices heard: Three case of public participation in environmental protection in China. J. Environ. Manag. 2012, 98, 65-72. [CrossRef] [PubMed]

55. Garard, J.; Kowarsch, M. If at first you don't succeed: Evaluating stakeholder engagement in global environmental assessments. Environ. Sci. Policy 2017, 77, 235-243. [CrossRef]

56. Vilchez, V.F.; Darnall, N.; Correa, J.A.A. Stakeholder influences on the design of firms' environmental practices. J. Clean. Prod. 2017, 142, 3370-3381. [CrossRef]

57. Coleman, S.; Hurley, S.; Koliba, C.; Zia, A. Crowdsourced delphis: Designing solutions to complex environmental problems with broad stakeholder participation. Glob. Environ. Chang. 2017, 45, 111-123. [CrossRef]

58. Cook, N.J.; Wright, G.D.; Andersson, K.P. Local politics of forest governance: Why NGO support can reduce local government responsiveness. World Dev. 2017, 92, 203-214. [CrossRef]

59. Foo, K. Examining the role of NGOs in urban environmental governance. Cities 2018, 77, 67-72. [CrossRef]

60. Li, G.Q.; He, Q.; Shao, S.; Cao, J.H. Environmental non-governmental organizations and urban environmental governance: Evidence from China. J. Environ. Manag. 2018, 206, 1296-1307. [CrossRef]

61. Lee, S.S. Network Analysis Methods Applications and Limitations; Cheong-Lam Press: Seoul, Korea, 2018.

62. Park, S.D.; Lee, J.Y.; Wang, B. The main factors affecting cultural exchange between Korea and China: A semantic network analysis based on the cultural governance perspective. Int. J. Intercult. Relat. 2019, 71, 72-83. [CrossRef]

63. Sung, B.; Park, S.D. Who drives the transition to a renewable-energy economy? Multi-actor perspective on social innovation. Sustainability 2018, 10, 448. [CrossRef]

64. Jung, K.; No, W.; Kim, J.W. Who leads nonprofit advocacy through social media: Some evidence from the Australian Marine Conservation Society's twitter networks. J. Contemp. Asia 2014, 13, 69-81. [CrossRef]

65. Jung, K.; Park, H.W. A semantic (TRIZ) network analysis of South Korea's "open public data" policy. Gov. Inf. Q. 2015, 32, 353-358. [CrossRef]

66. Park, S.D. The nexus of FDI, R\&D, and human capital on Chinese sustainable development: Evidence from a two-step approach. Sustainability 2018, 10, 2063.

67. Kwahk, K.Y. Social Network Analysis.; Chenglam Press: Seoul, Korea, 2014; pp. 355-357.

68. Rombach, M.P.; Porter, M.A.; Fowler, J.H.; Mucha, P.J. Core-periphery structure in networks. Siam. J. Appl. Math. 2014, 74, 167-190. [CrossRef]

69. Green, F.; Stern, N. China's changing economy: Implications for its carbon dioxide emissions. J. Clim. Policy. 2017, 17, 423-442. [CrossRef]

70. Zhang, L.; Mol, A.P.J.; He, G.Z. Transparency and information disclosure in China's environmental governance. Curr. Opin. Environ. Sustain. 2016, 18,17-24. [CrossRef]

71. Sun, X.Y.; Huang, R.G.; Yip, N.M. Dynamic Political Opportunities and environmental forces linking up; A case study of anti-PX contention in Kunming. J. Contemp. China. 2017, 26, 536-548. [CrossRef]

72. Borgatti, S.P.; Everett, M.G.; Freeman, L.C. Ucinet for Windows: Software for Social Network Analysis and Analytic Technologies; Harvard Press: Cambridge, MA, USA, 2002. 
73. Snyder, D.; Kick, E.L. Structural position in the world system and economic growth, 1955-1970: A multiple-network analysis of transnational interactions. Am. J. Sociol. 1979, 84, 1096-1126. [CrossRef]

74. Borgatti, S.P.; Everett, M.G. Models of Core/Periphery structures. Soc. Netw. 1999, 21, 375-395. [CrossRef]

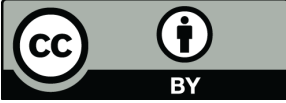

(C) 2019 by the authors. Licensee MDPI, Basel, Switzerland. This article is an open access article distributed under the terms and conditions of the Creative Commons Attribution (CC BY) license (http://creativecommons.org/licenses/by/4.0/). 